Working Paper 97-12 / Document de travail 97-12

A Micro Approach to the Issue of Hysteresis in Unemployment Evidence from the 1988-1990 Labour Market Activity Survey

by

Gordon Wilkinson

Bank of Canada Banque du Canada 
ISSN 1192-5434

ISBN 0-662-25852-5

Printed in Canada on recycled paper 
Bank of Canada Working Paper 97-12

May 1997

\section{A Micro Approach to the Issue of Hysteresis in Unemployment: Evidence from the 1988-1990 Labour Market Activity Survey}

by

Gordon Wilkinson

Bank of Canada 


\section{Acknowledgments}

The author would like to thank Allan Crawford, Jean-Francois Fillion, Irene Ip, David Longworth, Tiff Macklem, Brian O'Reilly, and Gerald Stuber for their helpful comments and suggestions in earlier drafts of this paper. The author also appreciates the assistance of Stephen Roller of Statistics Canada and the expert programming advice and support of Sylvain Plante. 


\begin{abstract}
This paper uses a rich set of microeconomic labour market data-the 1988-90 Labour Market Activity Survey published by Statistics Canada - to test whether there is negative duration dependence in unemployment spells. It updates and extends similar work carried out by Jones (1995) who used the 1986-87 Labour Market Activity Survey. Applying hazard model estimation, the analysis finds some evidence of negative duration dependence at the microeconomic level, which is consistent with the de-skilling hypothesis of hysteresis. These microeconomic estimates of negative duration dependence are used to compute macroeconomic estimates of hysteresis in unemployment. The results suggest that hysteresis effects from deskilling are very small at the macro level, contributing less than 0.1 percentage points to the aggregate unemployment rate. The small estimated size of this hysteresis effect may explain why evidence of hysteresis has been so difficult to find at the macroeconomic level. The paper also shows that Unemployment Insurance (UI) benefits reduce the probability of exiting from unemployment and that unemployment duration does not seem to be prolonged by reservationwage effects.
\end{abstract}

\title{
Résumé
}

L'auteur fait appel à une base de données microéconomiques très riche — soit les données de l'enquête de Statistique Canada portant sur l'activité du marché du travail pour les années 1988 à 1990 — afin d'établir si la probabilité de cesser d'être chômeur diminue à mesure que le chômage se prolonge. Il actualise et élargit les travaux analogues menés par Jones (1995) à l'aide des résultats de l'enquête de Statistique Canada relative aux années 1986 et 1987. Son analyse, qui repose sur l'estimation d'un modèle d'évaluation du risque, aboutit à des résultats qui appuient dans une certaine mesure l'existence d'une relation négative, au niveau microéconomique, entre la durée du chômage et la probabilité de cesser d'être chômeur, ce qui est conforme à l'hypothèse voulant que l'hystérèse soit due à l'érosion des compétences. À l'aide des estimations qu'il obtient au niveau microéconomique, l'auteur tente de chiffrer l'effet d'hystérèse dans le chômage au niveau macroéconomique. Selon ses résultats, l'effet d'hystérèse lié à l'érosion des compétences est très faible à l'échelle de l'économie et compterait pour moins de 0,1 point de pourcentage dans le taux de chômage global. La faiblesse de l'effet estimé pourrait expliquer que l'hystérèse soit si difficile à déceler au niveau macroéconomique. L'étude montre aussi que le versement de prestations d'assurance-chômage réduit la probabilité de cesser d'être chômeur et que les effets liés au salaire minimum exigé par un chômeur pour accepter un emploi ne semblent pas prolonger la durée du chômage. 



\section{Contents}

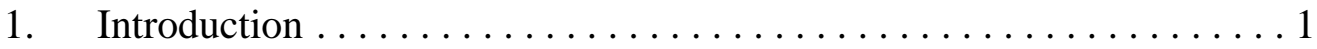

2. LMAS data base and hazard and survival functions $\ldots \ldots \ldots \ldots \ldots$

$2.1 \quad$ LMAS data $\ldots \ldots \ldots \ldots \ldots \ldots \ldots \ldots \ldots$

2.2 Hazard and survival functions $\ldots \ldots \ldots \ldots \ldots \ldots$

3. Hazard models . . . . . . . . . . . . . . . . . . . 7

3.1 Semi-parametric proportional hazards model $\ldots \ldots \ldots \ldots .7$

3.2 Parametric hazard specifications $\ldots \ldots \ldots \ldots \ldots \ldots$

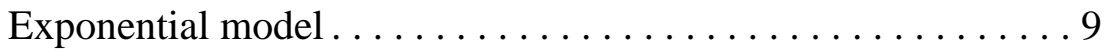

Weibull model $\ldots \ldots \ldots \ldots \ldots \ldots \ldots$

Log-normal model ..................

Gamma model ........................ 10

Generalized gamma model $\ldots \ldots \ldots \ldots \ldots \ldots \ldots$

Log-logistic model. ................... 11

4. Hazard function estimations for unemployment durations . . . . . . . 11

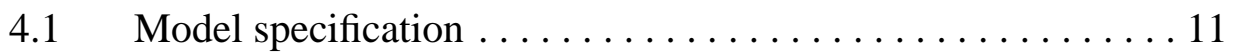

4.2 Estimations: Comparisons with Jones . . . . . . . . . . . 14

5. Hazard function estimations for re-defined employment durations. . . 15

$5.1 \quad$ Core model. . . . . . . . . . . . . . . . 15

$5.2 \quad$ Adding other variables $\ldots \ldots \ldots \ldots \ldots \ldots \ldots \ldots \ldots \ldots$

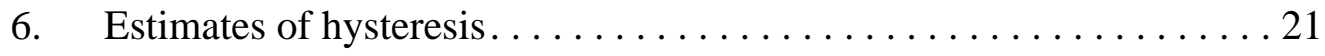

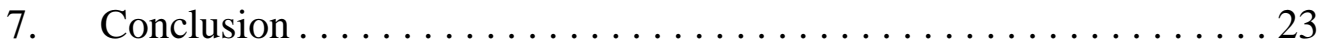

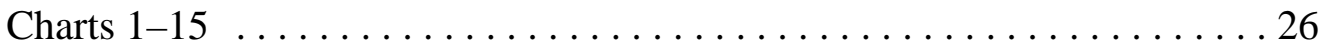

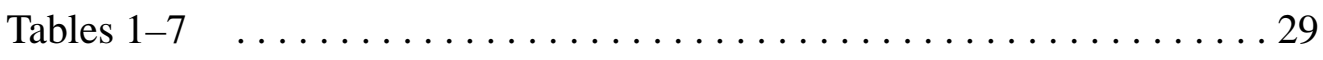

Bibliography ................................ 35

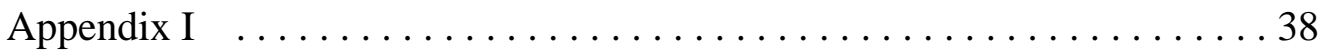



"After an initial period of considerable popularity, the hysteresis hypothesis has

lost some of its influence. This loss of favour appears to represent an empirical

judgement." Krugman (1994)

\section{Introduction}

The term "hysteresis," as applied to the labour market, refers to a condition whereby the unemployment rate rises or falls in response to some transitory shock and fails to return to its previous equilibrium level when the shock is over. In other words, changes in the unemployment rate are irreversible. The implication of hysteresis for monetary policy is that disinflation can be achieved only at a cost of a permanent increase in the rate of unemployment. A number of recent studies (Cozier and Wilkinson (1991), Poloz and Wilkinson (1992) and Jones (1995)) have failed to find support for the hysteresis hypothesis using Canadian macroeconomic data. ${ }^{1}$ Nevertheless, the theoretical arguments for hysteresis are sufficiently valid to warrant further investigation of this issue despite the lack of evidence at the macroeconomic level. One reason why it may be harder to find evidence of hysteresis at the macroeconomic level is that data at this level may be too aggregated for the size of the effect that is to be measured. Moreover, since many explanations for hysteresis are constructed around behaviours that take place at more disaggregated levels, the evidence of such behaviours may be easier to observe in data at a more micro level. Such data are provided by Statistics Canada's longitudinal data base, the Labour Market Activity Survey. This microeconomic data base, assembled from a large sample of Canadian households, contains a wide range of demographic, personal, and labour market information at the individual level. These data, when aggregated and weighted, are representative of the Canadian working-age population. This paper draws upon these microeconomic data in an effort to find evidence for hysteresis that may have been obscured at a more aggregate level.

A variety of theories have been developed to account for hysteresis. Two important ones are the "de-skilling" or the deteriorating human-capital hypothesis and the insider-outsider model of labour market segmentation. ${ }^{2}$ According to the "de-skilling" explanation of hysteresis, prolonged spells of unemployment may lead to an actual or a perceived erosion in an individual's

1. Fortin (1991) found some evidence of hysteresis at the macro level for adult males, although this result was not found to be robust in subsequent work by Poloz and Wilkinson (1992) and Jones (1995).

2. See Jones $(1995,16-26)$ for a more detailed review of these and some other theoretical explanations for hysteresis. 
skill level or work attitude, which in turn lowers the probability of finding a job and exiting from unemployment. This reduction in employability as a spell of unemployment drags on represents one channel by which an increase in the unemployment rate might not be reversed. According to the insider-outsider model of wage determination, individuals become unemployed and remain unemployed (that is, become outsiders) because those with jobs (insiders) settle for wage rates that are too high for periods of slack demand. Consequently, some workers lose their jobs during the temporary downturns and tend to remain unemployed because as "outsiders" they have no influence on the wage-setting process.

This study focusses on the human-capital or de-skilling explanation for hysteresis. If unemployment erodes skills, the longer an individual is unemployed, the more difficult it will be for him to find a job. The paper applies a micro-based statistical procedure called hazard function analysis to longitudinal data from Statistics Canada's 1988-90 Labour Market Activity Survey (LMAS) to assess whether the probability of exiting from unemployment does indeed decline as the length of the unemployment spell increases. The analysis is an update and extension of Jones (1995) who found mixed evidence for duration dependence in unemployment or nonunemployment spells using LMAS data covering the period 1986-87. As in Jones, many of the estimated hazard functions in the current study are downward-sloping, indicating that the probability of exiting from unemployment falls as the unemployment spell is prolonged. The extensions to Jones' work involve examining the impact of unemployment insurance benefits, cyclical effects, wage rates, and tenure on unemployment durations and deriving some macroeconomic estimates of hysteresis from the estimated hazard functions. It should be noted that the unemployment hazard functions of this paper, like those of Jones, are single-risk estimates that do not distinguish between transitions to work or out of the labour force. A single-risk approach was adopted in the current study because the hysteresis estimates derived from the hazard functions are applied to the Labour Force Survey unemployment rate, which embodies unemployed individuals that exit either to employment or outside the labour force. ${ }^{3}$

At the outset it should be noted that a downward-sloping hazard function at the microeconomic level may not imply duration dependence at the macroeconomic level. ${ }^{4}$ A simple example illustrates this point. Consider two different hiring rules used by firms. In both cases, the

3. This issue of single- or competing-risk models is irrelevant in Jones' non-employment hazard models which, by construction, involve only one transition-from non-employment to employment.

4. Blanchard and Diamond (1989). 
firms want to hire the same number of employees, so there are no implications for aggregate employment or unemployment. Under the first rule, the firms hire randomly, implying flat hazard functions. The alternative rule is that they hire the most recently employed worker. This latter rule would certainly result in a downward-sloping hazard function, but there is no hysteresis at the aggregate level since the unemployment rate is the same under both rules. Although this example may be extreme, it demonstrates the point that hysteresis at the aggregate level does not necessarily follow from a downward-sloping hazard function although it is suggested by such a function. Nevertheless, the stronger the evidence of duration dependence at the individual level, the greater may be the concern that this will show up at the aggregate level as hysteresis. Thus, by examining the micro evidence, it is possible to determine an upper bound to the effects of the duration dependence in unemployment on aggregate hysteresis. The estimates provided in this paper suggest that the influence of duration dependence in unemployment at the individual level on unemployment at the aggregate level is not large, which may explain why it has been difficult to identify hysteresis in many macroeconomic studies.

Work by Lauzon (1995), which was conducted independently but simultaneously with the current study and which focussed on spells of joblessness rather than spells of unemployment, also yielded downward-sloping hazard functions. Both the current study and Lauzon's paper employ the 1988-90 LMAS data base and use similar explanatory variables and parametric distributions for the estimated hazard functions. However, there are important differences between the two studies. The aims of the two studies are different and their results are not strictly comparable. Since the aim of the current study is to use estimates of hysteresis at the individual level as a means of estimating the degree of hysteresis in Statistics Canada's Labour Force Survey (LFS) definition of unemployment, an individual's period without work was defined to be as similar as possible to the LFS definition of unemployment. Hence, the unit of analysis in the current paper is the unemployment spell, defined as requiring active job search on the part of the jobless individual. Thus, discouraged workers are excluded from the analysis. In contrast, the unit of analysis in the Lauzon paper is the period of joblessness, defined as the number of weeks between the ending of one job and the start of another. Other differences between the two papers are that the current paper does not restrict unemployment spells to those arising solely from permanent layoff or firm closure; nor does it exclude young people living at home, the selfemployed, and agricultural and construction workers. Moreover, the current study adds a variable to control for the effects of UI benefits. 
The paper is organized as follows. Section 2 describes the LMAS microeconomic data base and the concepts of hazard and survival functions. Specific types of hazard models, both parametric and semi-parametric, are outlined in Section 3. Sections 4 and 5 present hazard model estimation results for unemployment and non-employment durations, compare these results with those of Jones (1995), and explore the sensitivity of these results to changes in estimation periods, changes in distributional assumptions, and the addition of new variables. Estimates of hysteresis are provided in Section 6 and a concluding summary follows in Section 7.

\section{LMAS data base and hazard and survival functions \\ 2.1 LMAS data}

The Labour Market Activity Survey (LMAS) is a longitudinal data base file published by Statistics Canada. The 1988-90 version of the LMAS data file provides detailed personal and labour market information on 55,434 individuals for the years 1988, 1989, and 1990. The information for 1988 was collected from a special supplement to the Labour Force Survey (LFS) in the month of January 1989 that covered approximately 40 thousand of the 48-thousand households sampled by the LFS. Information for subsequent years was obtained by special telephone and personal interviews of the same households one and two years later. Weights are available to make sample values representative of the Canadian population. Some of the personal information collected in the survey includes province of residence, marital status, gender, age, educational attainment, number of children, and visible-minority status. The labour market information covers details such as labour market status by week, average hourly wages for a given year, occupation, industrial sector, reasons for job absences and separations, job start and end dates, and union membership.

\subsection{Hazard and survival functions}

Survival and hazard function analysis is being used increasingly in economics to examine how exits from a particular economic state or condition evolve over time. Hazard models seem to be well suited for the identification of hysteresis in unemployment since they can isolate the influence of the passage of time on the probability of exiting from unemployment from economic, demographic, or personal effects. 
A survival function is defined as the unconditional probability that an individual or group of individuals remains in a particular state (i.e., unemployment) longer than duration $t$.

$$
S(t)=P(T>t)
$$

A non-parametric estimate of the survivor function, that is, one that does not control for differences in personal characteristics or labour market experiences across individuals, can be computed as the proportion of individuals remaining in a particular state longer than duration $t$.

$$
S^{E}(t)=\frac{(\text { Number of individuals remaining in the state longer than } t)}{(\text { Total number of individuals experiencing that state })}
$$

The 1988-90 LMAS data base contains 14,919 individual records with first spells of unemployment including those that are right-censored. ${ }^{5}$ The non-parametric estimate of the survival function for these spells is plotted on Chart 1 . It shows that only 20 per cent of the entire sample of first spells of unemployment lasted longer than 25 weeks. Less than 10 per cent of all first spells of unemployment extended beyond 40 weeks.

The survivor function has an underlying probability density function $f(t)$ that gives the unconditional probability that an individual will exit a state over a short interval $\Delta t$. This probability density function is expressed as:

$$
f(t)=\lim _{\Delta t \rightarrow 0} P\{\text { an individual exiting a state in interval } \Delta t\} / \Delta t .
$$

The probability density function $f(t)$ corresponding to the non-parametric survival function estimated by equation (2) is computed as the proportion of individuals exiting a state over a specified unit width:

$$
f^{\mathrm{E}}(t)=\frac{(\text { Number of individuals exiting a state in the interval } \Delta t)}{(\text { Total number of individuals experiencing that state } \mathrm{x} \Delta t)} .
$$

The non-parametric probability density curve for the 14,919 records of first spells of unemployment in the 1988-90 LMAS data base is shown in Chart 2. Each point along this curve represents the percentage of first spells of unemployment that were terminated at that

5. Some of the unemployment spells in the LMAS longitudinal data base are truncated. Unemployment spells that begin prior to the opening of the LMAS observation window and have unknown start dates are called left-censored spells. Spells that are still in progress at the end of the LMAS observation period and have unknown termination dates are called right-censored spells. Right-censored spells are included in the sample because the life-table method used to compute the non-parametric estimate of the survival function can adjust for these. Information on how the rightcensored spells are adjusted is given in $\operatorname{Kiefer}(1988,659)$. 
unemployment duration. Exits from first spells of unemployment over the period 1988-90 peaked at a rate of 10.5 per cent at 4 weeks of unemployment. The blip at 53 weeks is due almost entirely to the 103 LMAS records that show a transition from unemployment to out of the labour force at year-end 1989 because of recall errors between the annual data collection points. ${ }^{6}$

The hazard function is defined as the probability that an individual leaves a particular state at $t+\Delta t$ conditional on this individual occupying the state until $t{ }^{7}$ This function can be written as:

$$
\begin{gathered}
h(t)=\lim _{\Delta t \rightarrow 0} P\{\text { an individual who has remained in a state until } t \text { exits that state } \\
\text { in the interval } t+\Delta t\} / \Delta t .
\end{gathered}
$$

The non-parametric estimate of the hazard function is computed as the proportion of individuals exiting a state over a selected unit of time given that they were in that state at the beginning of the unit of time.

$$
h^{E}(t)=\frac{(\text { Number of individuals leaving a state in the interval } \Delta t \text { beginning at time } t)}{\text { (Number of individuals in that state at } t \times \Delta \mathrm{t})}
$$

The hazard function can take many distributional shapes. If the hazard function is rising, indicating that the probability of exit from a state increases as the time spent in that state lengthens, there is positive duration dependence. Such an outcome would arise if the discomfort associated with protracted periods of joblessness initiated more intensive job search, a greater willingness to accept less-than-ideal job offers, or a reduction in the reservation wage. ${ }^{8}$ If the hazard function is falling, there is negative duration dependence. This is the hysteretic outcome that would arise if workers with longer unemployment spells are viewed by employers as less skilled or productive than those with shorter spells. The hazard function could also remain constant or follow a more complicated process. This paper applies a wide variety of distributions to determine the appropriate shape of the hazard function for unemployment.

A non-parametric estimate of the hazard function for the 14,919 records of first spells of unemployment in the 1988-90 LMAS data base is depicted in Chart 3. This function has a

6. Recall errors refer to discrepancies in an individual's responses to survey questions from one year to the next. The resulting "seam" problem is discussed in Michaud, Egan, Lemaitre, and Murray (1991). The implications and treatment of this problem are discussed later in the paper.

7. The hazard function can also be expressed in terms of the survival and probability density functions: $h(t)=$ $f(t) / S(t)$. This expression shows that the hazard and survival functions are inversely related. Thus, higher hazard rates yield shorter average spells of unemployment.

8. Lancaster and Nickell $(1980,142)$ and Lynch $(1989,39)$. 
slight downward slope, indicating that the likelihood of leaving unemployment falls as unemployment duration lengthens. The prominent spike appearing in this estimated hazard function at week 53 is due mainly to the 103 LMAS records described earlier that show an abrupt transition from unemployment to out of the labour force at year-end 1989. Since the duration of UI benefits varies according to region and individual work experience, it is not surprising that the hazard function shows no bunching of exits from unemployment due to exhaustion of UI benefits.

Parametric or semi-parametric hazard models can be used to estimate the extent to which hysteretic behaviour has contributed to the downward-sloping pattern of the above hazard function. These models, which are discussed more fully in the next section, can disentangle the effect of passing time on the hazard rate from other influences. They also provide several other advantages over the more familiar linear regression probit or logit models: incomplete, rightcensored spells need not be excluded from the estimation; explanatory variables can be timevarying; and the estimated probability of departure from unemployment is permitted to vary with spell length.

\section{Hazard models}

\subsection{Semi-parametric proportional hazards model}

Since economic theory provides little guidance on the choice of functional form of the unemployment hazard function, the semi-parametric proportional hazards model developed by Cox (1972) is an attractive alternative because it allows the shape of the baseline hazard function to be determined by the data, not imposed. Unfortunately, the only means of identifying hysteresis with this approach is graphical inspection; there are no procedures to test the statistical significance of a particular outcome. In contrast, one important advantage of the parametric hazard models presented in Section 3.2 is that some structure is imposed on the distribution which allows for hypothesis testing.

The hazard rate in the proportional hazards model is represented by a function consisting of two components: (1) a vector of explanatory variables $x$ with unknown coefficients $B$, and (2) an unknown baseline hazard function $h_{0}(t)$ dependent solely on spell duration $t$ :

$$
h(t, x)=h_{0}(t) e^{x^{\prime} B} .
$$

The baseline hazard function $h_{0}(t)$ is defined as that rate of exit out of a state when all other influences except spell duration $t$ are excluded; that is, when all $x$ 's are equal to 0 so that 
$e^{x^{\prime} B}=1$. Thus, the baseline hazard function estimates the form of duration dependence. Evaluating the hazard function using mean values for the explanatory variables yields an estimated hazard function for the representative individual in the sample. By construction, the $x$ variables are restricted to be proportional to the baseline hazard $h_{0}(t)$. This means that variations in an explanatory variable affect the hazard rate by the same scale factor along the entire duration axis.

Cox (1975) introduced a method called partial-likelihood to estimate the parameters of the proportional hazards model. The partial-likelihood function is optimized by a NewtonRaphson algorithm. ${ }^{9}$ Right-censored and uncensored data are combined in such a way as to produce estimates that are asymptotically unbiased and normally distributed. ${ }^{10}$ Coefficient estimates may be interpreted in the same manner as OLS regression coefficients, with the sign and numerical value indicating the direction and size of the effect. ${ }^{11}$

Typically, a complete set of explanatory variables is required to produce a satisfactory estimate of the baseline hazard function. Omitting important regressors can yield results which incorrectly show negative duration dependency for unemployment if other factors such as age, lack of education, local economic conditions, or heterogeneous unobservables (such as motivation) are responsible for the reduced probability of leaving unemployment as an unemployment spell is prolonged. ${ }^{12}$

\subsection{Parametric hazard specifications}

With parametric methods, the distributional shape of unemployment durations can be pre-selected. Five of the more commonly used distributional forms are the exponential, the Weibull, the log-normal, the gamma, and the log-logistic distributions. The generalized gamma distribution, which includes the first four distributions as special cases, is the least restrictive parametric model and can be used to test the appropriateness of the more restrictive distributions. A brief description of each of these duration distributions is presented below.

9. For more details, see SAS Technical Report P-229 (1992, 452-453) and Lawless (1982, Appendix F, 528-531).

10. Allison (1984, 26, 34).

11. Allison $(1984,27)$.

12. See Kiefer (1988, 671-672); Lancaster and Nickell (1980, 144); Heckman and Borjas (1980, 259) and Alaouze (1987, 160). 


\section{Exponential model}

The one-parameter exponential distribution is characterized by a constant hazard rate. This distribution is referred to as "memoryless" because the rate of exit from a particular state is not affected by the length of stay in that state. By construction, the exponential model precludes hysteresis and its hazard function is represented mathematically as:

$$
h(t)=\lambda \text { where } \lambda>0 .
$$

\section{Weibull model}

The Weibull distribution has two parameters that allow for constant, positive, or negative duration dependence. The hazard function of this distribution is defined as:

$$
h(t)=\lambda \gamma(\lambda t)^{\gamma-1}
$$

where $\lambda>0$ determines the positioning of the hazard curve along the vertical axis $h(t)$ and $\gamma>0$ determines the shape of the hazard curve with respect to $t$. The hazard function is monotone increasing for values of $\gamma>1$ and monotone decreasing for values of $\gamma<1$. When $\gamma=1$, the Weibull distribution reduces to the exponential distribution and the hazard rate remains constant. The main advantage of the Weibull model is that the form of duration dependence-positive, negative, or constant-is estimated directly and is not imposed. This flexibility coupled with its mathematical simplicity makes it a particularly convenient means of testing for hysteresis.

\section{Log-normal model}

The log-normal distribution is suitable for hazard rates that rise initially to some maximum and then begin to decline as soon as the median is passed, gradually approaching 0 as $t$ approaches $\infty$. The hazard function of a log-normal distribution is completely specified by two parameters $\mu$ and $\sigma^{2}$, that are, respectively, the scale and shape parameters that determine the profile of this distribution. Mathematically, the hazard function of a log-normal distribution is defined as:

$$
h(t)=\frac{\frac{1}{t \sigma \sqrt{2 \pi}} \exp \left(\frac{-\left(\log (t-u)^{2}\right)}{2 \sigma^{2}}\right)}{1\left(-G\left(\log \frac{u t}{\sigma}\right)\right)}
$$

with mean $\exp \left(\mu+1 / 2 \sigma^{2}\right)$ and variance $\left[\exp \left(\sigma^{2}\right)-1\right] \exp \left(2 \mu+\sigma^{2}\right)$. The expression $G(\log (\mu t / \sigma))$ is the cumulative distribution function of a standard normal variate. The log-normal distribution is 
positively skewed. The larger the value of $\sigma^{2}$, the greater is the skewness. The higher the value of $\mu$, the lower is the value of the peak of the distribution.

\section{Gamma model}

Aging and failure processes have also been modelled using a gamma distribution, although less frequently than the Weibull because its survival and hazard functions are not expressed in simple algebraic forms. Like many of the previous models, it too is characterized by a scale parameter $\lambda$ and a shape parameter $\gamma$. When $\gamma$ is an integer, the hazard function of a gamma distribution is defined mathematically as:

$$
h(t)=\frac{\lambda(\lambda t)^{\gamma-1}}{(\gamma-1) ! \Sigma_{k=0}^{\gamma-1} \frac{1}{k !}(\lambda t)^{k}} .
$$

When $\gamma>1$, there is positive duration dependence and the hazard rate is monotone increasing from 0 to $\lambda$ as duration $t$ approaches $\infty$. When $0<\gamma<1$, there is negative duration dependence and the hazard rate is monotone decreasing from $\infty$ to $\lambda$ as duration $t$ approaches $\infty$. When $\gamma=1$, the gamma function is like the exponential function and has a hazard rate equal to $\lambda$ for all duration $t$.

\section{Generalized gamma model}

The generalized gamma distribution is the least restrictive of the parametric distributions and embraces the exponential, Weibull, log-normal, and gamma distributions as special cases. Thus, it is useful in assessing the appropriateness of applying one of the more restrictive distributions to a given data set. The hazard function of this distribution is represented mathematically as:

$$
h(t)=\frac{\frac{\lambda \beta}{\Gamma(k)} \cdot \lambda t^{k \beta-1} \exp \left(-(\lambda t)^{\beta}\right)}{1-I\left[k,(\lambda t)^{\beta}\right]}
$$

where $\beta, \lambda$ and $k \geq 0 .{ }^{13}$ The generalized gamma distribution follows a Weibull distribution when $k$ $=1$, an exponential when $\beta=k=1$, a log-normal when $k=0$, and a gamma when $\beta=1$.

13. See Lawless $(1982,19-26)$, for the derivation and definitions of $\Gamma(k)$ and $I\left[k,(\lambda t)^{\beta}\right]$. 


\section{Log-logistic model}

The log-logistic model provides a good approximation of the log-normal model. Its main advantage is that it offers algebraic expressions for the survivor and hazard functions that are simpler to manipulate than those of the log-normal, gamma, or generalized gamma distributions. The hazard function of the log-logistic distribution is expressed mathematically as:

$$
h(t)=\left(\lambda \gamma(\lambda t)^{\gamma-1}\right) /\left(1+(\lambda t)^{\gamma}\right)
$$

where $\gamma$ is the shape parameter and $\lambda$ is the scale parameter. A value of $\gamma>1$ produces a humped shape like that of the log-normal function with the hazard rising from 0 to a maximum at $t=(\gamma-$ $1)^{(1 / \gamma)} / \lambda$, then declining towards 0 as $t$ approaches $\infty$. A value of $\gamma<1$ produces a monotonic decreasing slope from $\infty$ while a value of $\gamma=1$ yields a monotonic decreasing slope from $\lambda$.

The type of hazard rate distribution that best characterizes unemployment duration is not clear a priori. Models showing downward-sloping hazard functions are the most appropriate for depicting the notion of hysteresis since they show that increasing time in unemployment reduces the chances of leaving. However, upward-sloping hazard models may be suitable if lengthy stays in unemployment result in an exhaustion of unemployment benefits which intensifies job search and encourages acceptance of available job offers. ${ }^{14}$ The hazard models estimated in the next section represent an attempt to uncover the kind of parametric hazard rate function that best describes the 1988-90 LMAS unemployment-duration data.

\section{Hazard function estimations for unemployment durations}

\subsection{Model specification}

Following Jones, the dependent variable in all estimated models is the duration of each individual's first spell of unemployment measured in weeks. Restricting the data to first spells of unemployment ensures that records with multiple spells are not double-counted in the estimation. Also, as in Jones, left-censored spells are excluded from the estimations. It appears that there is "no good remedy for the problem of left-censored spells." ${ }^{15}$ Right-censored spells are included in the estimations because they are easily handled in the likelihood estimation framework. ${ }^{16}$ All

\footnotetext{
14. Lancaster and Nickell (1980, 142).

15. Honig and Reimers $(1993,191)$.

16. Kiefer $(1988,668)$.
} 
parametric models are estimated using weighted LMAS data. ${ }^{17}$ These weights allow the sample data to be representative of the survey population.

In order to make appropriate comparisons with the study by Jones, the updated models use the same explanatory variables and parametric distributions. However, the comparisons are less than ideal given that Jones used a linked LMAS-LFS data base whereas the updated estimations are based solely on LMAS data. The linked data base corrects for the underestimation biases present in the computation of LMAS unemployment spells. ${ }^{18}$ The unemployment-duration data in the linked LMAS-LFS data base of Jones were derived from the LFS while the remaining information on personal characteristics was derived from the LMAS questionnaire. Unfortunately, time and financial constraints prohibited the use of a similar linked data base in my 1988-90 estimations. Nevertheless, the presence of downward biases in the LMAS unemployment data did not prevent the re-estimated models from yielding hysteretic outcomes. The estimated degree of hysteresis, however, may be understated by these data biases. Despite this shortcoming, the unlinked LMAS data set has two advantages over the linked LMAS-LFS data set: (1) unemployment-spell duration is not arbitrarily limited to a maximum of six months as it is in the linked data set; and, (2) the data sample is larger because it includes first-time unemployment spells commencing outside the six-month observation window of the linked data set.

As in Jones, this paper estimates traditional single-risk hazard models, which make no distinction as to the state of destination. Thus, these models assume that the hazard rate for transitions from unemployment to employment is the same as for transitions from unemployment to out of the labour force. Although not reported here, it was discovered that coefficient values of explanatory variables and the shape of the hazard were sometimes quite different when the hazard estimation was restricted to transitions involving a specific destination. However, single-risk estimation is more relevant for this paper given that the objective is to estimate hysteresis in the reported LFS unemployment rate, which is influenced by transitions to both employment and outside the labour force.

Each model in Table 1 includes four dummy variables to represent the region of residency in the year the unemployment spell began-either Atlantic Canada, Quebec, the

17. Estimation using weighted data is not an available option with the semi-parametric proportional hazards model. 18. See Jones and Riddell (1991). The design of the LMAS questionnaire limits the identification of unemployment spells to those that are continuous and terminate in a job or coincide with the year-end. Thus, the number of unemployment spells recorded by LMAS may be biased downward. 
Prairies, or British Columbia. These variables are designed to capture the influence of regional differences on spell duration relative to Ontario. Given that these regions had higher monthly unemployment rates than did Ontario over the 1988-90 sample period, it seems reasonable to expect that exit rates from unemployment would be lower in these regions and this suggests a negative coefficient on the residency dummy variables.

The influence of various personal characteristics on unemployment duration is captured by variables for: (1) gender-equal to 1 for males and 0 for females; (2) marital statusequal to 1 if married, otherwise 0; (3) visible-minority status-equal to 1 if a visible minority, otherwise 0; (4) number of children in 1989 under the age of 16; (5) age in 1988-ranging from 1 to 8 and corresponding to the following age groups-16 years, 17 to 19 years, 20 to 24 years, 25 to 34 years, 35 to 44 years, 45 to 54 years, 55 to 64 years, and 65 to 69 years; and (5) educational attainment in 1988 - ranging from 1 to 6 and corresponding to the following educational levels - 0 to 8 years of schooling, some secondary education, high school completion, some postsecondary education, post-secondary certificate or diploma, and university degree.

A positive coefficient is expected on the gender variable because employment equity and affirmative action programs were in their infancy or not as pervasive over the 1988-90 sample period and the hiring preference for male workers in some industries may have been more pronounced than in more recent years. Since financial commitments provide incentives for finding employment and tend to rise in proportion to family size (spouse and number of children), marital status and family size could have a positive effect on hazard rates. On the other hand, the effect of these variables would be negative if marriage and increasing family size reduce labour mobility. A positive coefficient was expected for the education variable, given that an individual's level of knowledge and work-related skills tend to rise with the number of years of education and given that these are often used by employers as a screening device in their hiring practices.

A negative coefficient may appear on the age variable if the predominant influence on hazard rates is the reluctance of employers to hire older workers. This reluctance may stem from impressions that older workers are less efficient, less trainable, less flexible, less productive, or less healthy and energetic than younger workers, or will provide fewer productive years of service for a given investment in training. However, if the main influence of age comes from seniority rules governing who is recalled first, the age coefficient may show a positive coefficient. A positive sign may also appear if age is used as a signal for work experience, although tenure, the 
number of years with a previous employer, represents a more direct measure of seniority or work experience. Such a variable is also tried in the hazard models presented later in the paper.

The visible-minority variable tests the importance of discriminatory hiring practices over the 1988-90 period when employment equity and affirmative action programs were in their infancy or not as widespread. This variable will yield a negative coefficient if discriminatory hiring practices were prevalent.

\subsection{Estimations: Comparisons with Jones}

Jones' original unemployment hazard model estimates, based upon the 1986-87 LMAS data base, are reported in Table 2. A comparison of the entries in columns A to E of Table 1 with those of the corresponding columns of Table 2 highlights the differences in coefficient values and significance levels between the updated and original set of hazard models. The updated hazard models show statistically significant negative coefficients for the Atlantic Canada, Quebec, Prairies, and British Columbia explanatory variables whereas only the Prairies variable was statistically significant in the original models. These results suggest that the unemployed living in regions outside Ontario have a lower probability of leaving unemployment. The statistical significance of the Prairies' variable in the original models seems inconsistent with LFS data over the 1986-87 period since, out of all regions, unemployment rates on the Prairies most resembled those of Ontario. This similarity in unemployment rates suggests similar unemployment hazard rates which should have yielded a statistically insignificant Prairies variable.

The updated hazard models also show that being "male" tends to have no effect on the probability of exiting from unemployment whereas a statistically significant negative coefficient appears on this variable in the models using the $1986-87$ data. ${ }^{19}$ According to the updated models, the likelihood of leaving unemployment rises with the number of years of education. This effect was absent in the original unemployment hazard models. However, both sets of models show that age tends to reduce hazard rates, although the effect seems to be stronger in the updated versions. The number-of-children variable is negative and statistically significant in most of the updated models but positive and statistically significant in all the hazard models based upon earlier data. Neither set of models provides evidence that the hazard rate is influenced by marital or visible-minority status.

19. Jones, however, does generate a positive "male" effect in his non-employment models (Table 4). 
In the semi-parametric proportional hazards model, the effect of duration on exits from unemployment is represented by the baseline hazard, which is calculated by evaluating the estimated proportional hazards model with all explanatory variables set to zero. As in the proportional hazards model estimated by Jones, that based upon 1988-90 LMAS data yields a baseline hazard that is downward-sloping (Chart 4). The downward slope indicates that the probability of exiting from unemployment falls as unemployment duration lengthens, just as predicted by the hysteresis hypothesis. ${ }^{20}$

The fully parametric hazard models also provide evidence supporting the hysteresis hypothesis. The Weibull, log-normal, log-logistic, and gamma hazard models generate declining hazard rates over all or most of the unemployment-duration continuum (Table 1). Except for the Weibull model, similar results were obtained in the Jones paper (Table 2). The updated Weibull and log-logistic hazard functions are plotted in Charts 5 and 6 . The log-logistic functions suggest that hazard rates rise in the early weeks of unemployment and then decline, with the rate of decline falling as spell duration lengthens. This pattern of rising and declining rates of exit from unemployment is more muted in the updated log-logistic model.

\section{Hazard function estimations for re-defined unemployment durations}

\subsection{Core model}

As noted earlier, the LMAS questionnaire produces by design a downward bias to the duration and number of unemployment spells recorded in the LMAS data base (Jones and Riddell (1991)). Jones responded to this problem by running hazard function models with a re-defined set of non-employment durations as the dependent variable. Because unemployment was the real object of interest, he modified his sample of non-employment durations to exclude full-year nonparticipants and those who reported leaving their first job because of retirement, ill health, personal reasons, or education. Hazard estimation results using these re-defined non-employment data are reported in Table 4. The signs and statistical significance of the explanatory variables of these models are more consistent with those of my updated unemployment models (Table 1) than those of Jones' unemployment models based upon the 1986-87 data (Table 2). Specifically, the Atlantic, Quebec, British Columbia, and years-of-education explanatory variables become statistically significant and yield the same signs as my updated unemployment models. Also, the

20. As a reminder, the spike at about week 53 is related to year-end seam/recall problems and involves about 100 sample observations. 
male variable changes sign from negative to positive and remains statistically significant. This similarity in results between the 1988-90 unemployment hazard models and Jones' 1986-87 redefined non-employment models suggests that the differences in estimation results between our unemployment-duration models most likely arise from Jones' use of the linked LMAS-LFS data base in his unemployment hazard models.

In order to correct for some of the downward biases in the duration and number of unemployment spells in the 1988-90 LMAS data base, three adjustments were made to create a re-defined set of first-time unemployment spells. The first adjustment changes all weeks coded as a period of non-employment (coded either as a 4 if out of the labour force or as a 3 if not looking for work but wanting work) as a period of unemployment (coded as a 2) if the period precedes or follows a year-end or year-beginning that is coded as a 2 and if the individual was not in school. This adjustment effectively eliminates much of the problem of discontinuous labour market states at year-end seams. The second adjustment re-codes all periods of non-employment following the first spell of employment as unemployment unless education, illness, personal responsibilities, or retirement were specified as reasons for leaving that job. The third adjustment re-codes a period of non-employment as unemployment if it only lasts from one to three weeks and interrupts a spell of unemployment. This last adjustment assumes that any highly abbreviated spell of nonemployment in the middle of an extended period of unemployment is due to coding error. For the remainder of the paper, this hybrid of LMAS unemployment and some non-employment data, which was created to compensate for the downward biases in the LMAS unemployment data, will be referred to as re-defined unemployment.

The hazard models using re-defined unemployment-duration data (Table 3) yield coefficient estimates that are similar to those produced by the unemployment-duration data (Table 1). The regional, age, and number-of-children explanatory variables are generally significant and negatively signed; the male and years-of-education explanatory variables are usually significant and positively signed; and the marital and visible-minority-status variables typically have no effect on the hazard rate. The negative sign on the number-of-children variable suggests that the female gender role, whereby larger numbers of children delay female exits from unemployment, is the dominating influence. ${ }^{21}$

21. This interpretation is supported in Lauzon (1995) which presents separate hazard model estimates for males and females in the 1988-90 LMAS sample and shows that having no children reduces spell length for women but raises it for men. 
The re-defined unemployment hazard models, like most of the unemployment hazard models presented in Tables 1 and 2, show that negative duration dependence is present over all of or much of the unemployment-duration continuum (see bottom line of Tables 3 and 4). This outcome provides additional support for the hysteresis hypothesis. The downward-sloping baseline hazard of the updated proportional hazards model using re-defined unemployment data is plotted in Chart 7. There is no longer a spike at week 53, indicating that the re-coding adjustments used to produce the re-defined unemployment data effectively treated the "seam" problem. Charts 8 and 9 plot the hazard functions of the Weibull and log-logistic re-defined unemployment hazard models against those of Jones. Both Weibull functions are downward-sloping while the loglogistic functions show a rising probability of exit in the early weeks of unemployment and a steady decline thereafter. This humped pattern is particularly pronounced in the updated loglogistic function.

\subsection{Adding other variables}

As noted before, hazard model estimation results are biased towards showing negative duration dependence if the set of explanatory variables is incomplete. Under such circumstances, the reduced probability of leaving unemployment as time progresses is incorrectly assigned to spell duration rather than to the missing influences. To minimize this bias, an expanded set of explanatory variables is used in the various re-defined unemployment hazard models presented in Table 5. Charts 10 and 11 provide a graphical representation of the impact of these additional explanatory variables on the estimated Weibull and log-logistic distributions. In both cases, the downward-sloping hazard function is less pronounced in the expanded model.

The seasonal dummies in the expanded hazard models measure whether the duration of a re-defined unemployment spell is influenced by the month in which the spell started. Jones experimented with a monthly seasonal dummy in his models although he omitted it from published results because it had "no effect on the other results." ${ }^{22}$ All model specifications exclude the month of July so, by construction, all parameter estimates represent the influence of the particular month in which a spell starts, relative to July. Estimation results show that, relative to spells begun in July, hazard rates are lower for spells begun in January, February, August, September, October, and November.

22. Jones $(1995,99)$. 
Unemployment durations can be prolonged not only by "de-skilling” but by periods of weak demand conditions. A cyclical variable was incorporated into the hazard model in order to avoid misassigning the effects of weak demand on unemployment duration to hysteresis. The absence of a cyclical variable was not critical in the Jones' models because the 1986-87 LMAS data came from the same expansionary phase of the business cycle. However, this is not the case with the 1988-90 data set which straddles both an expansionary and contractionary phase of the business cycle. Thus, it appears that some cyclical variable is needed to capture the change in underlying macroeconomic conditions from which these re-defined unemployment-spell data are generated. The variable used to represent cyclical effects in the various hazard models of Table 5 is the regional unemployment-rate gap prevailing at the moment of exit. ${ }^{23}$ This cyclical variable produces the expected negative coefficient and suggests that the conditional probability of exiting from unemployment falls by about 40 per cent for every percentage point that the regional unemployment rate exceeds its trend rate. ${ }^{24}$

In order to eliminate the possibility that the estimated hysteresis effect may be biased downwards because of some circularity between the unemployment-rate-gap covariate and the dependent variable, unemployment duration, ${ }^{25}$ a Weibull hazard model that uses capacity utilization as the cyclical covariate instead of the unemployment-rate gap was estimated. (Detailed results are not reported.) The capacity utilization covariate was statistically significant and exhibited the expected positive sign, indicating that the conditional probability of exiting unemployment improves as capacity utilization tightens. However, the estimated value for $\gamma$ was statistically greater than one, which yielded a hazard function with a positive slope and offered no support for hysteresis. Given that the capacity utilization rate is limited to a quarterly frequency and is not available on a regional basis, it is probably a less appropriate measure of cyclical influences than the unemployment-rate gap. Thus, results from models including such a variable seem less likely to be reliable.

23. In the absence of estimated-equilibrium unemployment rates by region, these were proxied by an average of monthly LFS regional unemployment rates over the 1988-90 period.

24. Taking the exponent of the estimated parameter, subtracting one, and multiplying by 100 "gives the percentage change in the hazard for each unit change in the explanatory variable." See Allison (1984, 28). Thus, [(exp 0.53)$1]^{*} 100=41 \%$.

25. It does not seem that the risk of circularity is excessively strong since, for most of the 1988-90 period, the unemployment-duration data come from a source (i.e., LMAS) that is relatively independent of the source used for the unemployment-rate data (i.e., LFS). The maximum overlap between the two sources of data would be the first six months of the LMAS sample. 
A variety of studies have shown that exhaustion of UI benefits has an important influence on exits from unemployment. ${ }^{26}$ This result is supported by the expanded hazard models of Table 5. These models yield a statistically significant negative coefficient on the weeks-of-UIbenefits variable, indicating that the conditional probability of exiting a spell of unemployment rises as the UI benefit stream is shortened. ${ }^{27}$

The expanded re-defined unemployment hazard models also include industry sector and occupational explanatory variables to measure the influence of industrial sector or the occupation of an individual's previous job on unemployment duration. The public administration sector is excluded from the set of industry explanatory variables so, by design, all industry effects are expressed in relation to public sector jobs. The estimation results in Table 5 typically show that only the unemployed who previously worked in construction and in the transportation and communication sectors have a conditional probability of leaving unemployment that is higher than those who previously worked in public administration. Those with no previous employment (i.e., no SIC/SOC code) are the only group of unemployed with a conditional probability of leaving unemployment that is lower than those who previously worked in the public sector. For the remaining industry sectors, the conditional probability of departure is not significantly different from that in the public administration sector.

The set of occupational explanatory variables excludes clerical jobs, so by construction the model presents occupational effects in relation to clerical occupations. Those previously employed in sales, processing, and materials-handling occupations typically show a conditional probability of leaving unemployment that is statistically higher than for those in clerical jobs. In some hazard models, managerial occupations have a lower rate of exit.

There are a number of first spells of unemployment in the LMAS data base that are very short because the individual has already found a new job while on the old job and uses this as the reason for leaving the old job. A variable to control for this effect on the unemployment hazard rates was also incorporated into the expanded models. Not unexpectedly, the estimation results in Table 5 show that the probability of exiting from unemployment is substantially higher for those who left a job because they found another job than for those who left or lost a job for other reasons.

26. Jones $(1995,70)$ and Belzil $(1995,124)$.

27. The number of weeks of UI benefits received by an unemployed individual is not provided directly by the LMAS so it was estimated. Details of the estimation procedure appear in Appendix I. 
Wages earned in a previous job are often identified as an influence on job-search activities during a spell of unemployment and have also been included as a variable in the expanded models. ${ }^{28}$ A negative sign on this variable suggests that previous earnings operate as a reservation wage such that persons accustomed to higher earnings hold out for jobs with similar high rates of pay. This behaviour reduces the probability of leaving unemployment and prolongs the unemployment spell. However, the estimated coefficient has a positive sign, which indicates that there is no reservation-wage effect that prolongs unemployment durations. Instead, it seems that employers may be using previous hourly wage rates to evaluate the quality of job applicants, resulting in faster rehiring for those unemployed who have lost or left higher-paying jobs. Interpreted in terms of labour supply, the positive sign may also be indicating that unemployed individuals are using their previous hourly wage as the opportunity cost of non-employment. Thus, the better the pay in the last job, the more intense is the job search, and the faster is the exit from unemployment.

Tenure, measured as the difference between the stop and the start week of the job preceding the period of unemployment, was also included as a variable in the expanded models in order to capture seniority, work experience, or human-capital effects. Those with no work experience are excluded from the set of tenure explanatory variables so the tenure effects must be interpreted in relation to those with no work experience. Estimation results generally show that tenure has little influence on the probability of exiting unemployment except for the unemployed with one to less than five years of work experience. This group of unemployed shows a rate of exit from unemployment that is statistically faster than the group with no tenure. Such a result suggests that a certain amount of work experience may improve the probability of leaving unemployment. However, the absence of such an effect for those with longer periods of tenure suggests that firm-specific experience over a more extended period of time is less beneficial, perhaps because potential employers view the skills of such persons as obsolete or less relevant in the new job or because the unemployed person limits the scope of the job search to the same field as the previous job.

28. The wage variable used in the expanded models is not strictly the hourly wage in the previous job but the average hourly wage rate including tips, commissions, bonuses, and paid overtime that the unemployed person received from an employer in 1988. 


\section{Estimates of hysteresis}

At the microeconomic level, hysteresis in unemployment has been framed in terms of negative duration dependence, that is, the reduced probability of exiting from unemployment with the passage of time. This hysteresis effect can be depicted graphically as the gap between some horizontal "non-hysteretic" hazard line, representing an unchanged probability of exit, and some downward-sloping "hysteretic" hazard line, representing a declining rate of exit. The declining "hysteretic" line is generated using model estimates for $\gamma$ and $\lambda$. The horizontal "non-hysteretic" line is determined using model estimates for $\lambda$, which is the intercept for the $h(t)$ axis, but imposing a value of one on $\gamma$ so that the probability of exiting from unemployment always remains at the same rate as in the first week of unemployment. ${ }^{29}$ By taking this line as the "nonhysteretic" control line, the aggregate implications of duration dependence at the individual level are maximized. To see this, suppose that the non-hysteretic or "control" hazard line is drawn horizontally across the "hysteretic" downward-sloping curve such that the sum of the probability deviations in excess of the average random-probability line is equal (in absolute value terms) to the sum of the probability deviations below the average random-probability line. In this case, the positive and negative probability deviations are exactly offsetting, so there is no hysteresis in aggregate.

Going back to our original assumption that the non-hysteretic "control" is equal to the same probability of exit in the first week of unemployment as estimated by the hysteretic line, the hysteresis effect in the expanded re-defined unemployment Weibull model (Table 5, column A) would be represented as the gap between the downward-sloping estimated hazard function with $\gamma$ $=0.93$ and $\lambda=0.165$ and the horizontal line with $\gamma$ and $\lambda$ set equal to 1.0 and 0.165 , respectively (Chart 12). The estimated $\lambda=0.165$ represents the probability of exiting unemployment during the first week of unemployment. Therefore, in the non-hysteretic "control," where the probability of exiting unemployment is not affected by unemployment duration, the probability of leaving unemployment remains at 0.165 for all spells of unemployment.

Using a few simple mathematical operations, a numerical value, measured in terms of the aggregate unemployment rate, can be assigned to the wedge-shaped hysteresis effect

29. Although a horizontal line could have been estimated using the exponential model, the results may not be valid if this distributional assumption of constant hazard rates is imposed even though a declining rate is more appropriate. When this approach was tried, the non-hysteretic control estimated by the exponential model fell completely below the "hysteretic" line estimated by the Weibull model, implying that rates of exit from unemployment are faster in the presence of duration dependence! 
portrayed in Chart 12. The baseline survival functions corresponding to the horizontal and downward-sloping hazard functions of Chart 12 are depicted in Chart 13. The percentage difference between the average unemployment durations computed from these two survival functions is 3.5 per cent. This is an estimate of the extent to which hysteresis prolonged unemployment durations on average during the period 1988-1990. Given that the unemployment rate $=$ incidence of unemployment $\mathrm{x}$ duration of unemployment, ${ }^{30}$ the effect of hysteresis on unemployment duration can be transformed into an estimate of its effect on the unemployment rate. The expanded Weibull model suggests that hysteresis may have raised the unemployment rate by an average of 3.5 per cent during the period 1988-1990 with a 95 per cent confidence interval of 2.9 to 4.2 per cent (Table 6). For every percentage point increase in the unemployment rate, this estimate implies that hysteresis contributes about 0.03 to 0.04 percentage points. A much higher estimate for hysteresis (i.e., 7.5 per cent) is generated when the Weibull model is restricted to a narrower set of variables (i.e., the same set used by Jones). This result illustrates how the estimate of negative duration dependence is biased upwards by excluding relevant variables. When the same mathematical operations are applied to Jones' Weibull model based upon nonemployment durations, the estimate of hysteresis is much smaller (4.0 per cent with a range of 3.5 to 4.4 per cent) even though the same narrower set of variables is used. The likely reason the estimate for duration dependence is smaller even with a smaller set of explanatory variables is that one of the more important excluded variables - the cyclical variable - was not a relevant factor in the 1986-87 period and so the results are not biased upwards by its exclusion.

It should be reiterated that the above estimates represent, in terms of the unemployment rate, the amount of time by which unemployment spells have been prolonged by hysteresis effects. These estimates cannot be interpreted as the percentage of the unemployed population that remains permanently in a state of unemployment since the estimated survival curve in Chart 13 shows that no unemployment duration would last beyond 60 weeks once the various factors that could influence unemployment duration, including hysteresis, are taken into consideration.

Weibull distributions are often used in studies of duration dependence because of their mathematical and expositional simplicity. Moreover, these distributions offer a convenient framework to test for hysteresis since they allow the data to choose among three well-defined

30. Gunderson and Riddell (1993, 624). 
options-positive, constant, or negative duration dependence. Unfortunately, Lagrange Multiplier chi-square results for restrictions on the extended generalized gamma model (Table 7) suggest that the specified functional forms - the exponential, Weibull, log-normal, and gamma-do not approximate unemployment-duration data as well as the extended gamma distribution. According to the log-likelihood estimates, the closest approximation of the extended gamma distribution is the log-normal distribution. This outcome suggests that the re-defined unemployment data are represented better by a rising then falling log-normal distribution than by a monotonically declining Weibull distribution.

The log-logistic model, reported in column B of Table 5, is a good approximation of the log-normal distribution and yields the lowest log-likelihood estimate next to the log-normal, which suggests that it will likely provide a better estimate of hysteresis than the Weibull (Table 7). The log-logistic model estimates a hysteresis effect of 6.3 per cent with a 95 per cent confidence interval of 5.4 to 7.2 per cent (Chart 14 and Table 6). This estimate assumes that the nonhysteretic or "control" hazard rate remains constant at 0.077 , which is the rate of exit from unemployment in week one estimated by the log-logistic model. Although the log-logistic hysteresis effect is larger than that estimated by the Weibull model, it remains small in relation to the overall unemployment rate, which may explain why most macroeconomic studies have failed to detect hysteresis.

The estimated hysteresis effect from the proportional hazards model with an expanded set of explanatory variables is 4.9 per cent (Chart 15, Table 5, Column D, and Table 6). This estimate assumes that the non-hysteretic "control" for the hazard rate remains at 0.134 , which is the estimated rate of exit from unemployment in week one. Although the hysteresis effect estimated by this model is larger than the Weibull estimate, it remains small in relation to the overall unemployment rate and provides further evidence that hysteresis effects may not be large enough to be identified using customary macroeconomic procedures.

\section{Conclusion}

Jones applied hazard models to the 1986-87 LMAS unemployment and nonemployment data and found some evidence of hysteretic effects in unemployment and nonemployment at the microeconomic level. This paper re-estimates these equations using new data from the 1988-90 LMAS and adds new explanatory variables to the original set. The updated and expanded estimation results also provide some support for hysteresis. However, the estimated 
upper bound for these hysteretic effects is small-between 3 and 8 per cent of the unemployment rate, or equivalent to about 0.03 to 0.07 percentage points when the unemployment rate rises by one percentage point. The fact that the upper bound of this effect is estimated to be quite small may explain why hysteresis effects have been difficult to detect in many macroeconomic studies.

There are a number of important caveats attached to these hysteresis estimates. First, they will be biased downwards to the extent that there are forms of hysteresis at the aggregate level that are not adequately captured by measures of duration dependence at the micro level. Secondly, these estimates may be biased by sampling and non-sampling problems with the LMAS, although the size and direction of these biases are not clear. The LMAS, unlike the LFS, does not allow for new labour market entrants. Thus, as time goes on, its population ages and becomes somewhat less representative of the true population. As well, recall error in the LMAS data is considerably higher than in the LFS data given that it surveys events further in the past. However, some of these errors have been removed by the adjustments made for discontinuous labour market states at year-end seams described earlier in the paper. The estimates of hysteresis may also be affected by imputations made for survey respondents who provided information in only two out of the three survey years. Non-respondents, who reduced the original sample of households by 18 per cent, do not affect the estimates directly as they are excluded from the data base. However, the precision of the estimation results would have been improved by the addition of information from non-respondents. Finally, these estimates of hysteresis will be biased as discouraged workers and part-time workers who want full-time work are excluded from the current measure of aggregate unemployment.

With due consideration of the shortcomings listed above, the results of this paper tend to reinforce the conclusions drawn in earlier macroeconomic studies on hysteresis that the bulk of the costs of disinflation are temporary. The paper shows that a portion of the unemployed indeed face diminishing prospects of leaving unemployment the longer they remain unemployed, but their share in the overall unemployment rate is small. Moreover, there was no evidence that unemployment durations were being prolonged by a reservation-wage effect. In fact, the opposite was true with the unemployed who had previously held higher-paying jobs exiting unemployment at faster rates.

In 1993 Statistics Canada launched a new longitudinal labour market survey called the Survey of Labour and Income Dynamics (SLID). Extending the estimation procedures presented in this paper to the more recent labour market data available on SLID may help assess the extent 
to which the estimates of hysteresis may have been affected by recent structural changes in the Canadian labour market. Moreover, the coding of unemployment spells has improved, which should result in better quality estimates. 
CHART 1: Survival function for the first spells of unemployment from the 1988-1990 LMAS data base

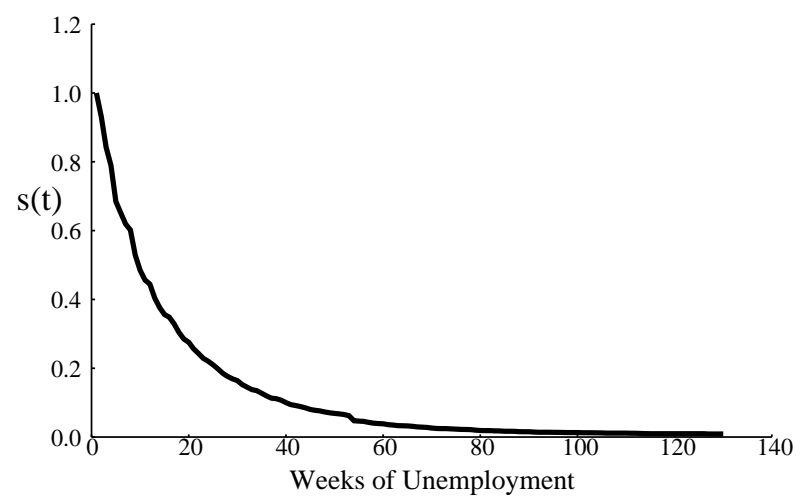

CHART 2: Probability density function for the first spells of unemployment from the 1988-1990 LMAS data base

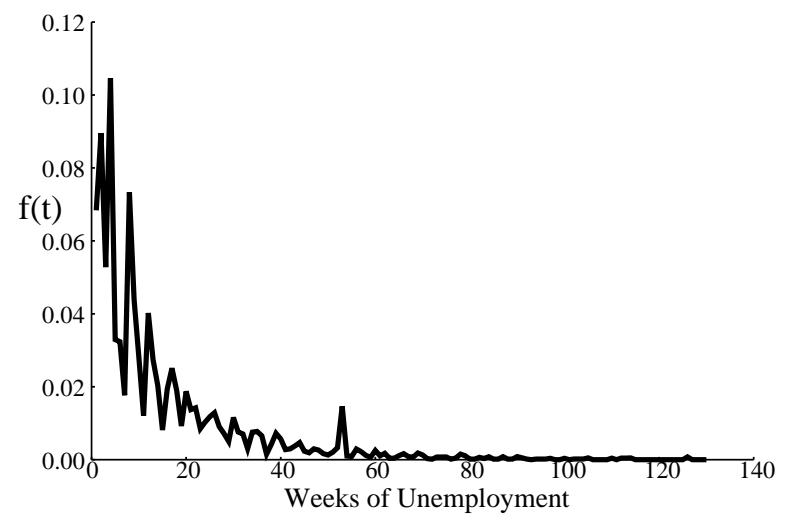

CHART 3: Hazard function for first spells of unemployment in the 1988-1990 LMAS data base ${ }^{1}$

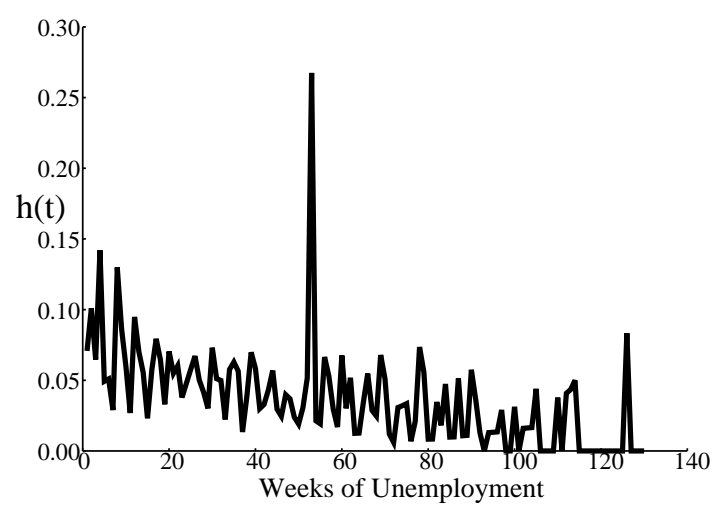

CHART 4: Baseline hazard estimated from proportional hazards model: unemployment durations, 1988-90, Table 1, Column A

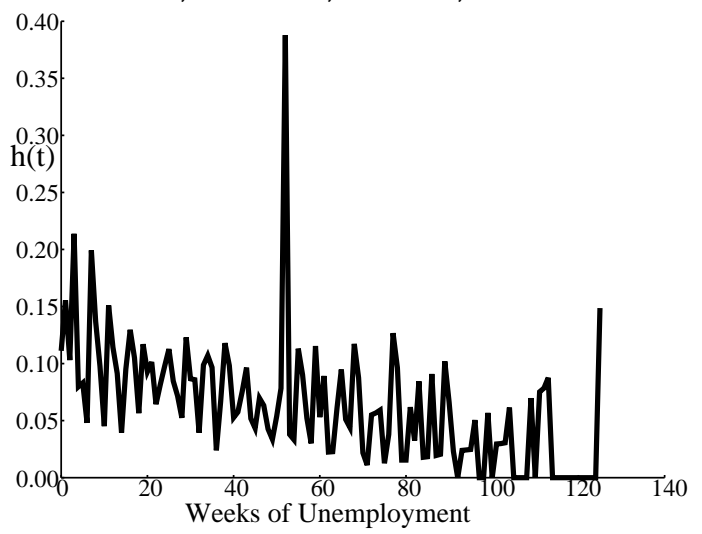

CHART 5: Hazard function estimated from Weibull model: unemployment durations, 1988-90, Table 1, Column C

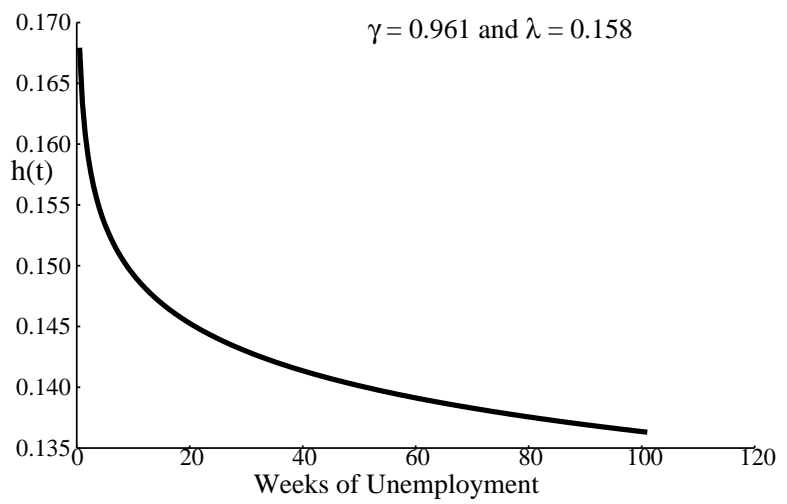

CHART 6: Hazard functions estimated from loglogistic models using unemployment durations, Column E of Tables 1 and 2

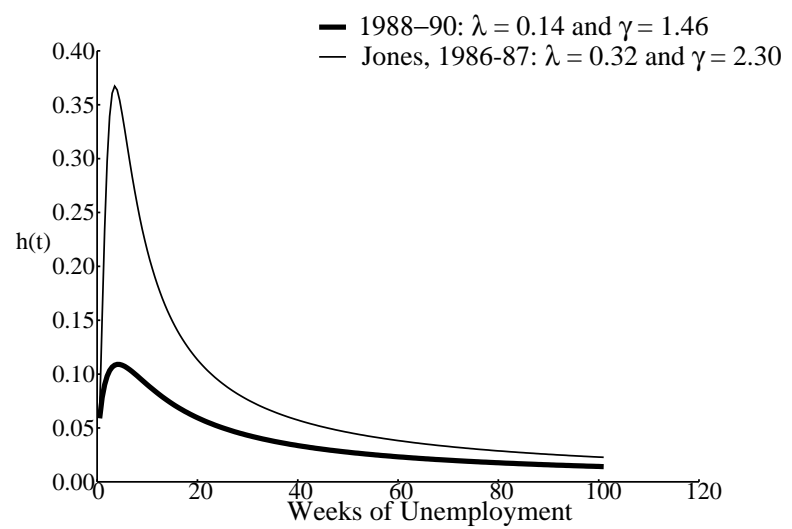


CHART 7: Baseline hazard estimated from proportional hazards model: re-defined unemployment durations, 1988-90, Table 3, Column A

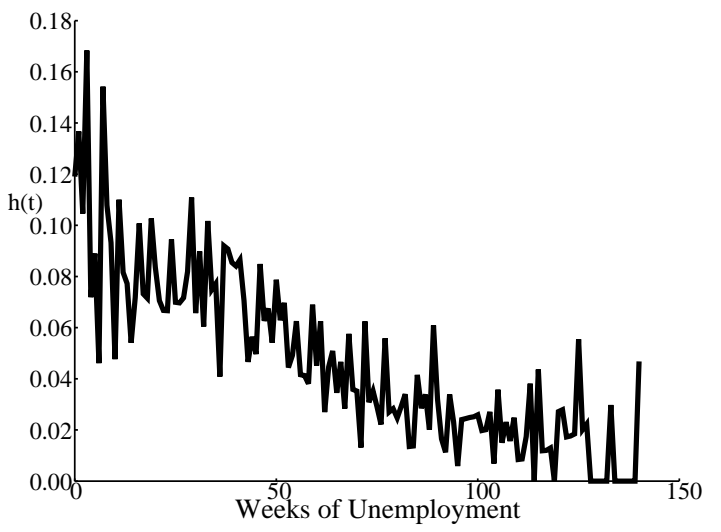

CHART 8: Hazard functions estimated from Weibull models using re-defined unemployment durations, Column C of Tables 3 and 4,

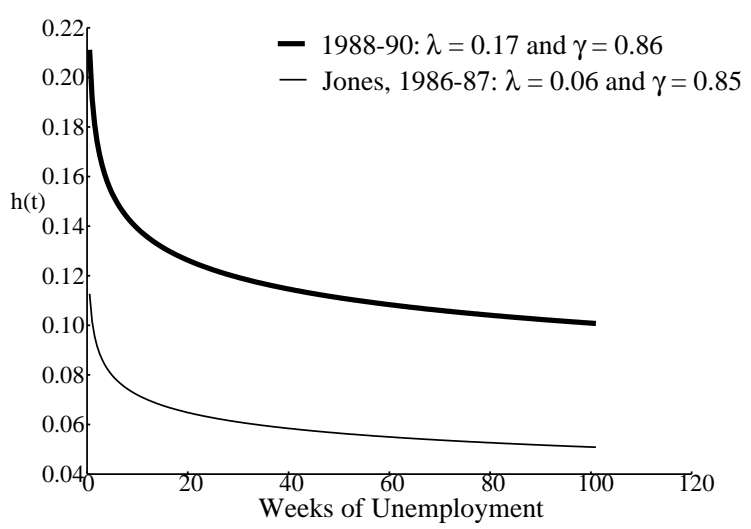

CHART 9: Hazard functions estimated from log-logistic models using re-defined unemployment durations, Column E of Tables 3 and 4

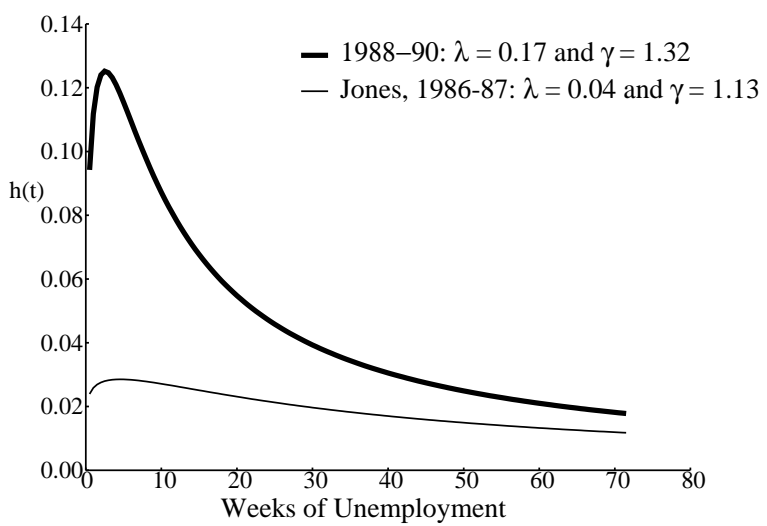

CHART 10: Hazard functions estimated from Weibull models: re-defined unemployment durations, 1988-90, Column C, Table 3 and Column A, Table 5

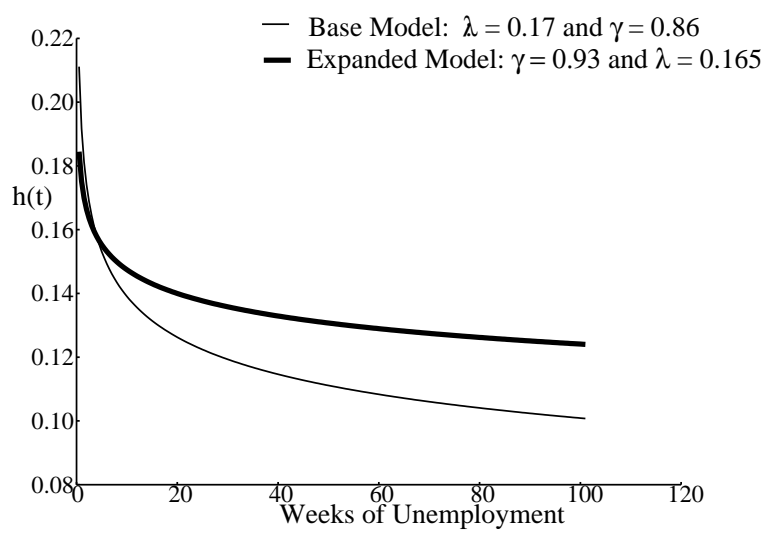

CHART 11: Hazard functions estimated from loglogistic models: re-defined unemployment durations, 1988-90, Column E, Table 3 and Column B, Table 5

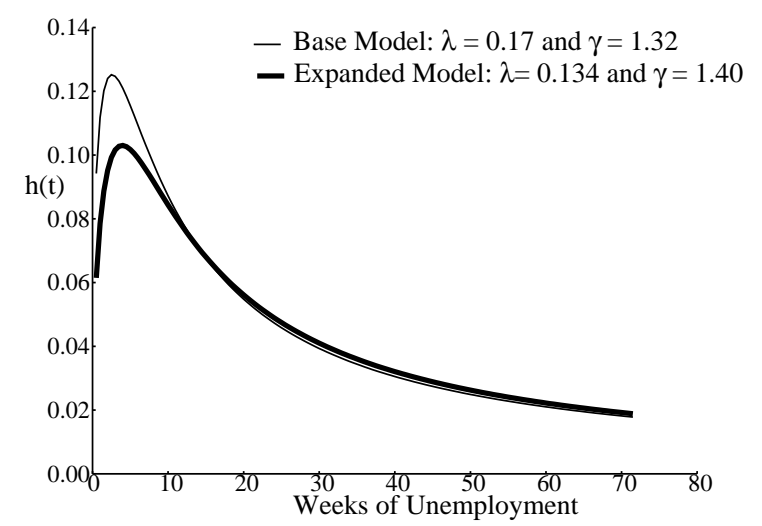

CHART 12: Hazard function estimated from expanded Weibull model: re-defined unemployment durations, 1988-90, Table 5, Column A

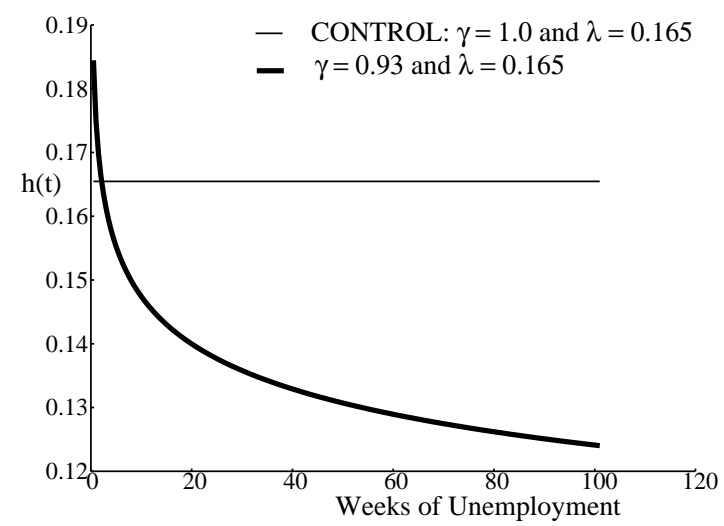


CHART 13: Survival function for the Weibull model in Chart 12

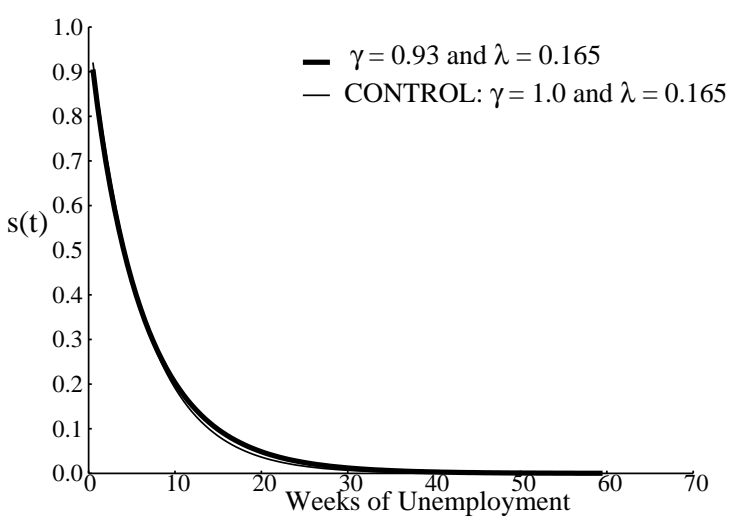

CHART 14: Hazard estimated from expanded log-logistic model: re-defined unemployment durations, 198890, Table 5, Column B

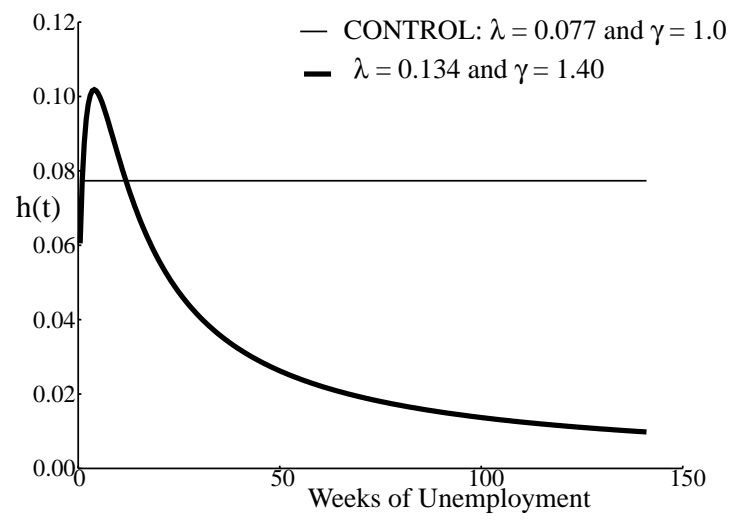

CHART 15: Baseline hazard estimated from expanded proportional hazards model: re-defined unemployment durations, 1988-1990, Table 5, Column D

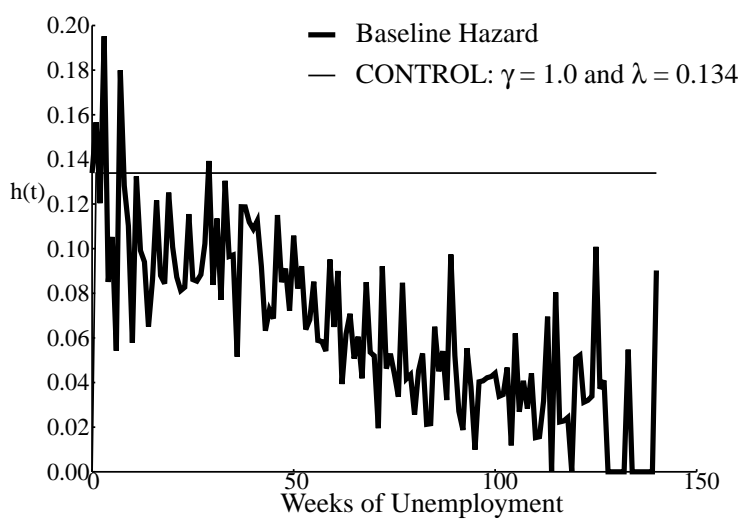




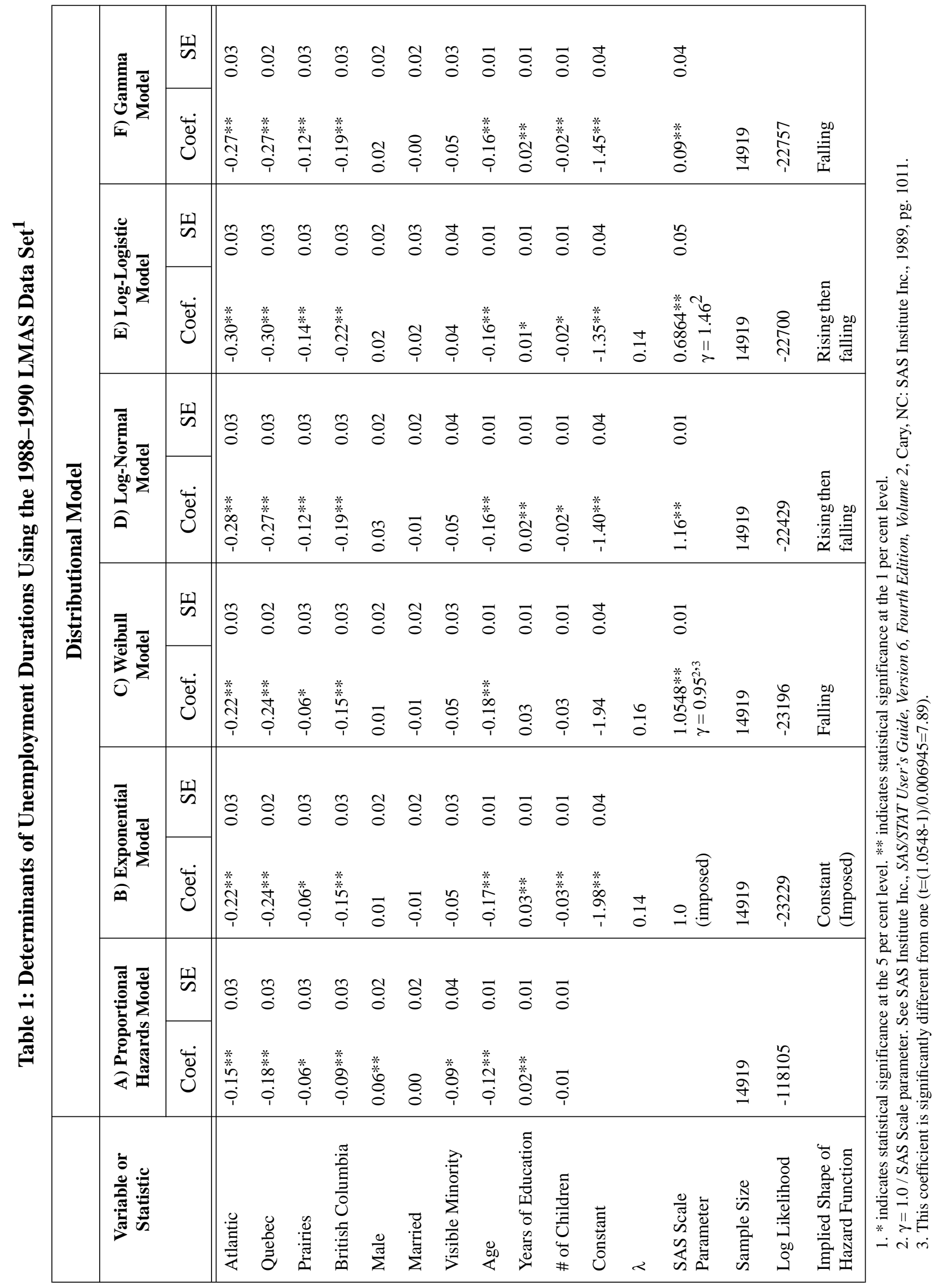


ర్లి

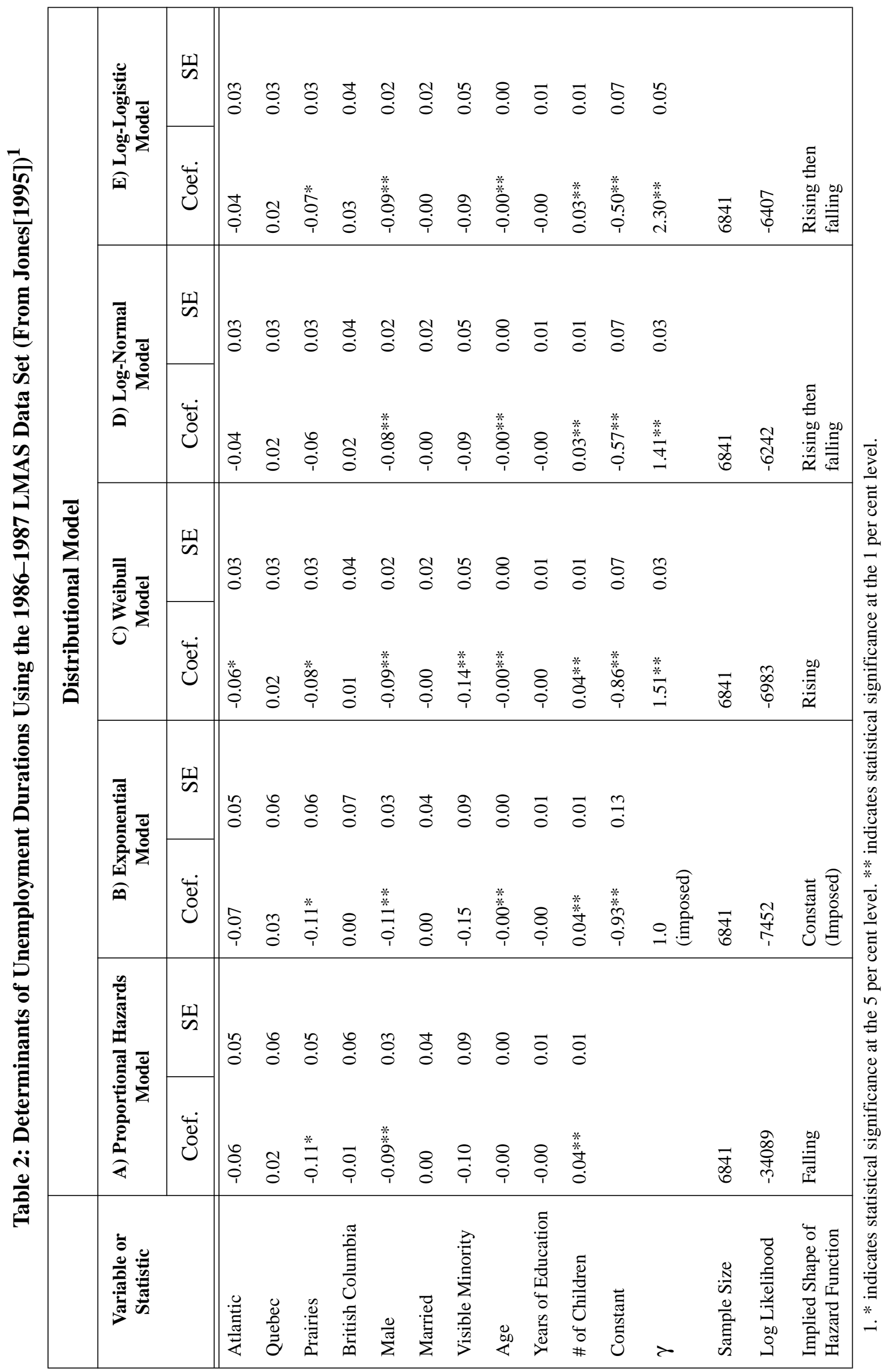




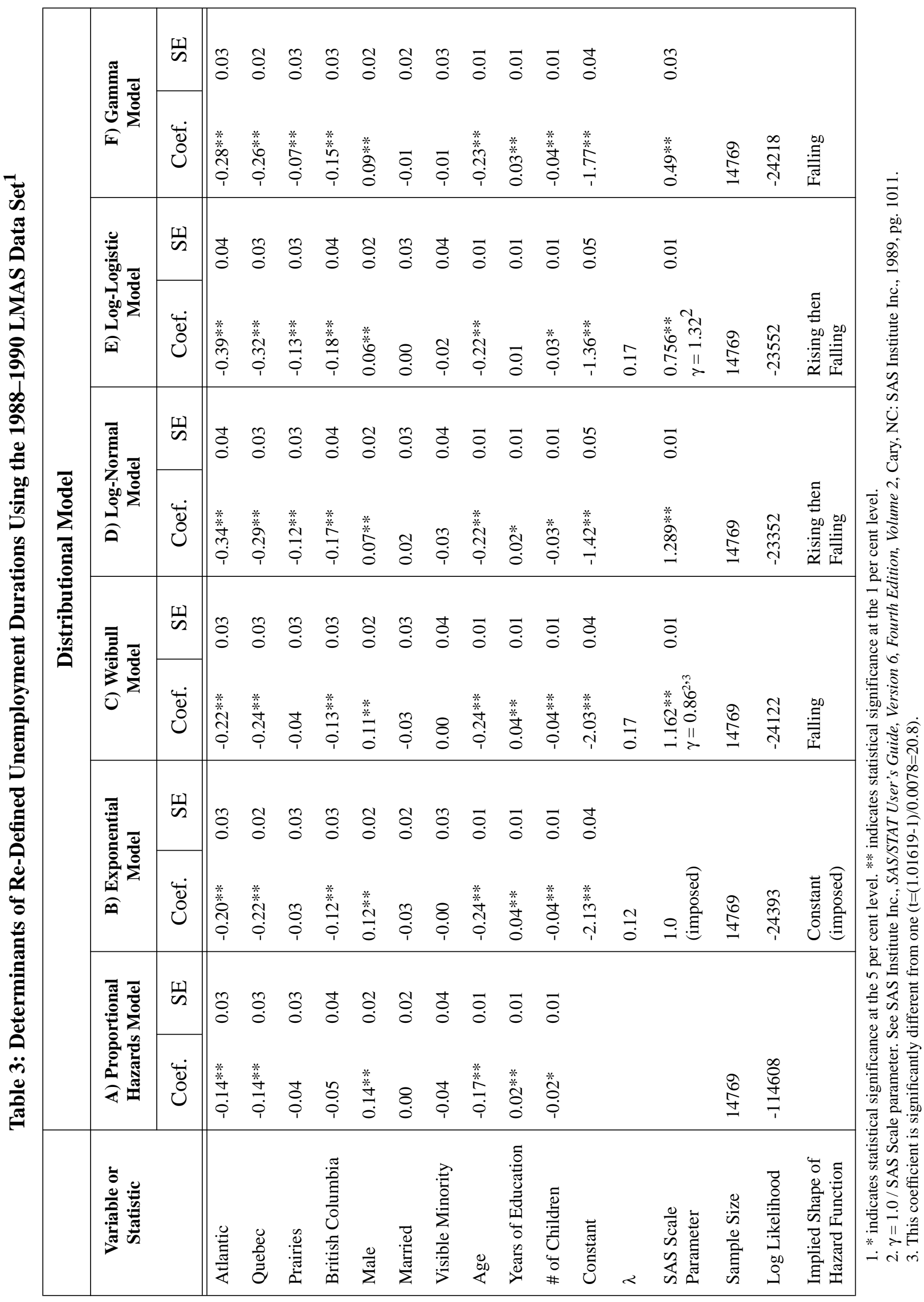




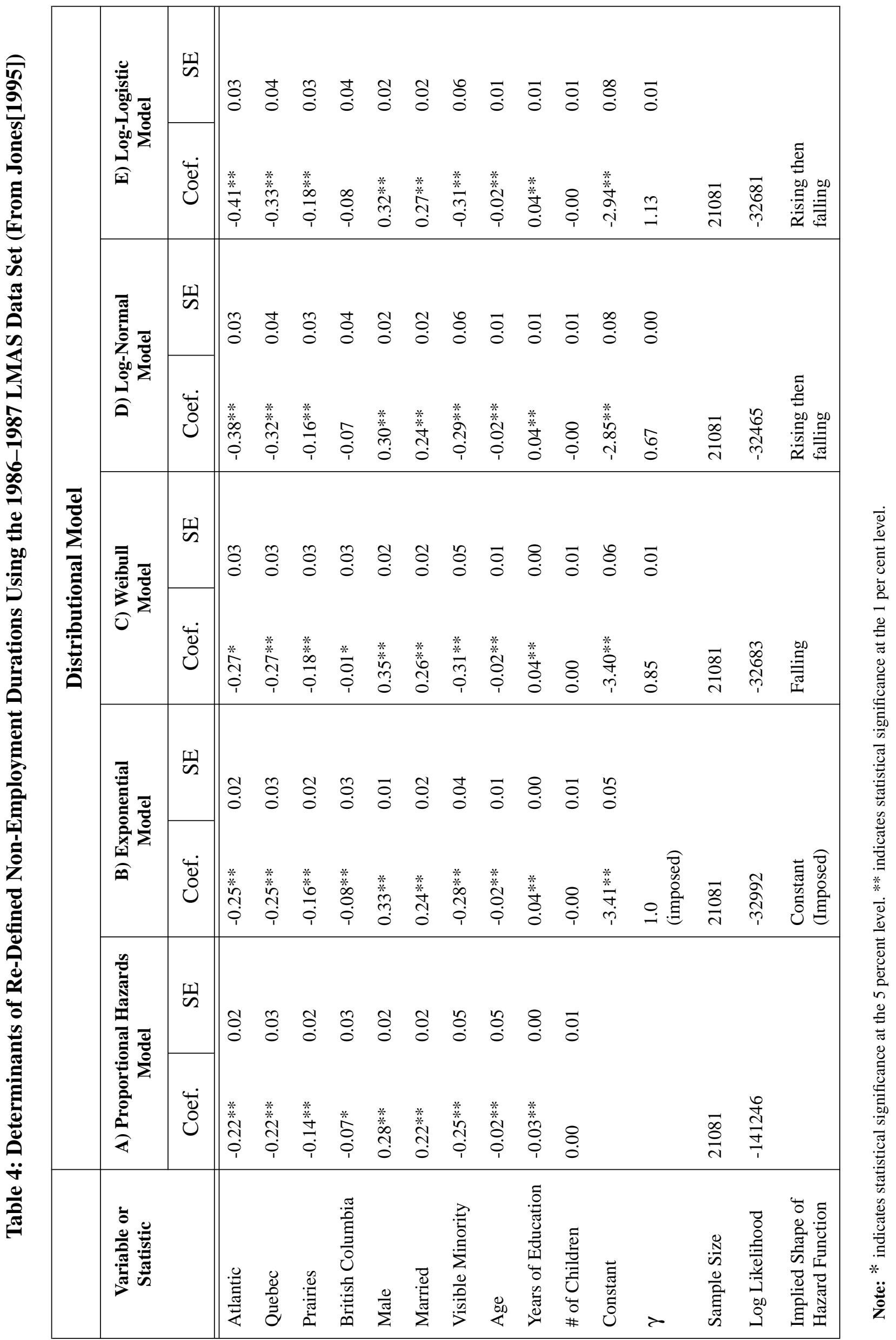


Table 5: Determinants of Re-Defined Unemployment Durations Using the 1988-1990 LMAS Data Base and An Expanded Set of Explanatory Variables

\begin{tabular}{|c|c|c|c|c|c|c|c|c|}
\hline & \multicolumn{8}{|c|}{ Distributional Model } \\
\hline Variable or Statistic & \multicolumn{2}{|c|}{$\begin{array}{l}\text { A) Weibull } \\
\text { Model }\end{array}$} & \multicolumn{2}{|c|}{$\begin{array}{l}\text { B) Log-logistic } \\
\text { Model }\end{array}$} & \multicolumn{2}{|c|}{$\begin{array}{l}\text { C) Generalized } \\
\text { Gamma Model }\end{array}$} & \multicolumn{2}{|c|}{$\begin{array}{l}\text { D) Proportional Hazards } \\
\text { Model }\end{array}$} \\
\hline Atlantic & $-0.29 * *$ & 0.03 & $-0.30^{* *}$ & 0.04 & $-0.29 * *$ & 0.04 & $-0.18 * *$ & 0.03 \\
\hline Quebec & $-0.15 * *$ & 0.03 & $-0.19 * *$ & 0.03 & $-0.18 * *$ & 0.03 & $-0.10 * *$ & 0.03 \\
\hline Prairies & $-0.08 * *$ & 0.03 & 0.04 & 0.03 & -0.01 & 0.03 & $-0.06^{*}$ & 0.03 \\
\hline British Columbia & $-0.17 * *$ & 0.03 & $0.14 * *$ & 0.04 & 0.04 & 0.04 & $-0.09 *$ & 0.04 \\
\hline Male & $0.08 * *$ & 0.02 & $0.06 * *$ & 0.02 & $0.07 * *$ & 0.02 & $0.12 * *$ & 0.02 \\
\hline Married & 0.01 & 0.02 & 0.06 & 0.03 & 0.05 & 0.03 & 0.02 & 0.02 \\
\hline Visible Minority & 0.01 & 0.04 & -0.05 & 0.04 & -0.04 & 0.04 & -0.03 & 0.04 \\
\hline Age & $-0.17 * *$ & 0.01 & $-0.16^{* *}$ & 0.01 & $-0.16^{* *}$ & 0.01 & $-0.14 * *$ & 0.01 \\
\hline Years of Education & $0.03 * *$ & 0.01 & $0.02 * *$ & 0.01 & $0.02 * *$ & 0.01 & $0.02 * *$ & 0.01 \\
\hline \# of Children & $-0.04 * *$ & 0.01 & $-0.04 * *$ & 0.01 & $-0.04 * *$ & 0.01 & $-0.03 * *$ & 0.01 \\
\hline January & $-0.21 * *$ & 0.05 & $-0.28 * *$ & 0.05 & $-0.23 * *$ & 0.05 & $-0.27 * *$ & 0.03 \\
\hline February & $-0.17 * *$ & 0.05 & $-0.21 * *$ & 0.06 & $-0.18 * *$ & 0.05 & $-0.17 * *$ & 0.05 \\
\hline April & $-0.10 *$ & 0.05 & $-0.14 * *$ & 0.05 & $-0.13 * *$ & 0.05 & -0.08 & 0.04 \\
\hline May & -0.01 & 0.05 & -0.05 & 0.05 & -0.03 & 0.05 & 0.00 & 0.04 \\
\hline June & -0.07 & 0.04 & -0.09 & 0.05 & -0.08 & 0.05 & -0.03 & 0.04 \\
\hline August & $-0.20 * *$ & 0.05 & $-0.15^{* *}$ & 0.05 & $-0.16^{* *}$ & 0.05 & $-0.21 * *$ & 0.04 \\
\hline September & $-0.21 * *$ & 0.05 & $-0.17 * *$ & 0.05 & $-0.16^{* *}$ & 0.05 & $-0.26^{* *}$ & 0.04 \\
\hline October & $-0.20 * *$ & 0.05 & $-0.22 * *$ & 0.06 & $-0.19 * *$ & 0.05 & $-0.24 * *$ & 0.04 \\
\hline November & $-0.22 * *$ & 0.05 & $-0.25^{* *}$ & 0.06 & $-0.24 * *$ & 0.05 & $-0.23 * *$ & 0.05 \\
\hline December & -0.05 & 0.05 & -0.01 & 0.05 & -0.02 & 0.05 & -0.08 & 0.04 \\
\hline Regional Unemployment Rate Gap & $-0.53 * *$ & 0.01 & $-0.54 * *$ & 0.01 & $-0.53^{* *}$ & 0.01 & $-0.35^{* *}$ & 0.01 \\
\hline Weeks of UI Benefits & $-0.01 * *$ & 0.00 & $-0.01 * *$ & 0.00 & $-0.01 * *$ & 0.00 & $-0.01 * *$ & 0.00 \\
\hline Agriculture/Fishing/Forestry & 0.04 & 0.07 & 0.10 & 0.08 & 0.08 & 0.08 & 0.06 & 0.06 \\
\hline Mining Industry & 0.10 & 0.10 & 0.16 & 0.11 & 0.11 & 0.11 & 0.12 & 0.08 \\
\hline Manufacturing Industry & -0.04 & 0.05 & 0.09 & 0.06 & 0.05 & 0.06 & 0.05 & 0.05 \\
\hline Construction Industry & $0.16^{*}$ & 0.07 & $0.19 *$ & 0.07 & $0.16^{*}$ & 0.07 & 0.07 & 0.06 \\
\hline Trans., Comm. Industry & $0.16^{*}$ & 0.06 & $0.23 *$ & 0.07 & $0.17 *$ & 0.07 & 0.10 & 0.06 \\
\hline Comm., Bus. \& Pers. Serv. & 0.05 & 0.05 & 0.07 & 0.05 & 0.05 & 0.05 & 0.06 & 0.04 \\
\hline No SIC/SOC Code & $-0.44 * *$ & 0.08 & $-0.42 * *$ & 0.08 & $-0.48 * *$ & 0.08 & $-0.50 * *$ & 0.07 \\
\hline Managerial Occupations & -0.06 & 0.05 & $-0.17^{*}$ & 0.05 & $-0.12 *$ & 0.05 & $-0.10 *$ & 0.05 \\
\hline Professional Occupations & 0.05 & 0.04 & 0.09 & 0.04 & 0.08 & 0.04 & 0.02 & 0.04 \\
\hline Sales Occupations & $0.13^{* *}$ & 0.04 & $0.09 *$ & 0.05 & $0.10^{*}$ & 0.05 & 0.03 & 0.04 \\
\hline Service Occupations & 0.03 & 0.04 & 0.08 & 0.04 & 0.06 & 0.04 & 0.02 & 0.03 \\
\hline Primary Occupations & 0.02 & 0.05 & -0.06 & 0.06 & -0.03 & 0.06 & 0.03 & 0.04 \\
\hline Processing Occupations & $0.14 * *$ & 0.04 & $0.11 * *$ & 0.05 & $0.12 * *$ & 0.05 & 0.05 & 0.04 \\
\hline Construction Occupations & -0.02 & 0.06 & -0.03 & 0.07 & -0.01 & 0.06 & 0.04 & 0.05 \\
\hline Materials Handling Occ. & $0.14^{* *}$ & 0.04 & $0.16^{* *}$ & 0.05 & $0.17 * *$ & 0.05 & $0.10 *$ & 0.04 \\
\hline Found New Job & $0.42^{* *}$ & 0.07 & $0.73 * *$ & 0.08 & $0.61 * *$ & 0.08 & $0.24 * *$ & 0.07 \\
\hline Average Hourly Wage in ' 88 & $0.01 * *$ & 0.00 & $0.01 * *$ & 0.00 & $0.01 * *$ & 0.00 & $0.01 * *$ & 0.00 \\
\hline Tenure: 0 to $<1$ year & -0.07 & 0.04 & 0.08 & 0.04 & 0.03 & 0.04 & 0.01 & 0.04 \\
\hline Tenure: 1 to $<5$ years & 0.05 & 0.03 & $0.09 *$ & 0.03 & $0.08 *$ & 0.03 & $0.11 * *$ & 0.03 \\
\hline Tenure: 5 to $<10$ years & -0.00 & 0.04 & 0.06 & 0.05 & 0.04 & 0.05 & 0.04 & 0.04 \\
\hline Tenure: 10 to $<20$ yrs. & 0.04 & 0.05 & 0.00 & 0.05 & -0.00 & 0.05 & 0.08 & 0.05 \\
\hline Tenure: 20 yrs. \& over & $-0.19 *$ & 0.09 & -0.18 & 0.09 & -0.15 & 0.09 & -0.09 & 0.08 \\
\hline Constant & $-1.94 * *$ & 0.07 & $-1.43^{* *}$ & 0.08 & $-1.54 * *$ & 0.08 & & \\
\hline SAS Scale Parameter $(\beta)$ & 1.0 (imposed) & & $0.71 * * \gamma=1.40$ & 0.01 & $1.20 * *$ & 0.01 & & \\
\hline SAS Shape Parameter $(k)$ & $1.08 * * \gamma=0.93$ & 0.01 & & & $0.22 * *$ & 0.03 & & \\
\hline Sample Size & 14603 & & 14603 & & 14603 & & 14603 & \\
\hline Log Likelihood & -22308 & & -22136 & & -21886 & & -112241 & \\
\hline Implied Shape of Hazard Fc. & Falling & & Rising then falling & & Rising then $\mathrm{f}$ & & & \\
\hline
\end{tabular}

1. * indicates statistical significance at the 5 per cent level. ** indicates statistical significance at the 1 per cent level. 
Table 6: Hysteresis Effects Estimated from Various Re-Defined Unemployment Hazard Models

\begin{tabular}{|l|c|c|c|}
\hline \multicolumn{1}{|c|}{ Model } & $\begin{array}{c}\text { Hysteresis Effect as } \\
\text { a Percentage Share } \\
\text { of the } \\
\text { Unemployment Rate } \\
\text {-- Point Estimate } \\
\text { a Percentage Share } \\
\text { of the } \\
\text { Unemployment Rate } \\
\text {--Range }\end{array}$ & $\begin{array}{c}\text { Hysteresis Effect In } \\
\text { Percentage Points } \\
\text { Arising From a One } \\
\text { Percentage Point } \\
\text { Increase in the } \\
\text { Unemployment Rate }\end{array}$ \\
\hline Jones -- Weibull, 1986-87, Table 4, Column C & $4.0 \%$ & 3.5 to 4.4\% & 0.04 \\
\hline Weibull -- 1988-90, Table 3, Column C & $7.5 \%$ & 6.7 to $8.4 \%$ & 0.07 \\
\hline $\begin{array}{l}\text { Weibull -- expanded set of explanatory varia- } \\
\text { bles -- 1988-90, Table 5, Column A }\end{array}$ & $3.5 \%$ & 2.9 to 4.2\% & 0.03 \\
\hline $\begin{array}{l}\text { Log-Logistic -- expanded set of explanatory } \\
\text { variables -- 1988-90, Table 5, Column B }\end{array}$ & $6.3 \%$ & 5.4 to 7.2\% & 0.06 \\
\hline $\begin{array}{l}\text { Proportional Hazards -- expanded set of explan- } \\
\text { atory variables--- 1988-90, Table 5, Column D }\end{array}$ & $4.9 \%$ & & 0.05 \\
\hline
\end{tabular}

Table 7: Lagrange Multiplier Chi-Square Test Results for Distributional Assumptions

\begin{tabular}{|l|l|l|l|l|}
\hline \multirow{2}{*}{$\begin{array}{c}\text { Distributional } \\
\text { Assumption }\end{array}$} & \multicolumn{3}{|c|}{ Restrictions } & Log Likelihood \\
\cline { 2 - 5 } & $k=1$ & $\beta=1$ & $k=0$ & \\
\hline Exponential & 476.5 & 123.8 & & -22377 \\
\hline Weibull & 1970.8 & & & -22308 \\
\hline Log-Normal & & & 70.0 & -21921 \\
\hline Gamma & & 658.3 & & -22235 \\
\hline Log-Logistic & & & & -22136 \\
\hline
\end{tabular}




\section{Bibliography}

Addison, John T. and Pedro Portugal. 1987. "On the Distributional Shape of Unemployment Duration." The Review of Economics and Statistics 69 (August): 520-526.

Alaouze, Chris M. 1987. "Empirical Evidence on the Sign of the Slope of the Hazard Rate from Unemployment from a Fixed Effects Model.” Journal of Applied Econometrics 2(2): $159-168$.

- 1984. "The Hazard Rate From Unemployment When the Search Environment is Characterised by a Decreasing Probability of Offer.” Economics Letters 16: 381-385.

Allison, Paul D. 1984. Event History Analysis: Regression for Longitudinal Event Data. Beverly Hills, CA: Sage Publications.

Barnes, Walter, David Hartzell, Dennis Kraft, Kerry D. Vandell and William Wendt. 1993.

“Commercial Mortgage Defaults: Proportional Hazards Estimation Using Individual Loan Histories." Journal of the American Real Estate and Urban Economics Association 21(4): 451-480.

Belzil, Christian. 1995. "Unemployment Insurance and Unemployment Over Time: An Analysis With Event History Data." The Review of Economics and Statistics 77 (February): 113-126.

Bergstrom, R. and P. A. Edin. 1992. "Time Aggregation and the Distributional Shapes of Unemployment Duration.” Journal of Applied Econometrics 7: 5-30.

Blanchard, Olivier J. and Peter Diamond. 1989. "The Beveridge Curve.” Brookings Papers on Economic Activity 1: 1-51.

Blanchard, Olivier J. and Lawrence H. Summers. 1986. "Hysteresis and the European Unemployment Problem.” In NBER Macroeconomics Annual, edited by S. Fischer, 15-78. Cambridge, MA: MIT Press.

Cox, David R. 1975. "Partial Likelihood.” Biometrika 62 (1975): 269-276. - 1972. "Regression Models and Life-Tables." Journal of the Royal Statistical Society. Series B, 34(2): 187-220.

Cozier, Barry and Gordon Wilkinson. 1991. Some Evidence on Hysteresis and the Costs of Disinflation in Canada. Technical Report No. 55. Ottawa: Bank of Canada.

Fortin, Pierre. 1991. "The Phillips Curve, Macroeconomic Policy and the Welfare of Canadians." Canadian Journal of Economics 24: 774-803.

Groot, Wim. 1990. "Heterogeneous Jobs and Re-employment Probabilities." Oxford Bulletin of Economics and Statistics 52: 253-267.

Gunderson, Morley and W. Craig Riddell. 1993. Labour Market Economics. 3rd ed. Toronto: McGraw-Hill Ryerson. 
Hannan, Michael T. and Nancy Brandon Tuma. 1984. Social Dynamics: Models and Methods. New York: Academy Press.

Heckman, James J. and George J. Borjas. 1980. “Does Unemployment Cause Future Unemployment? Definitions, Questions and Answers from a Continuous Time Model of Heterogeneity and State Dependence.” Economica 47 (August): 247-283.

Honig, Marjorie and Cordelia Reimers. 1993. "The Perceived Budget Constraint under Social Security: Evidence from Re-entry Behaviour.' Journal of Labour Economics 11(1, Pt. 1) (January): 184-204.

Hujer, Reinhard and Hilmar Schneider. 1989. "The Analysis of Labour Market Mobility Using Panel Data.” European Economic Review 33: 530-536.

Imbens, G. W. 1994. "Transition Models in a Non-Stationary Environment." The Review of Economics and Statistics 76(4)(November): 703-720.

Jones, Stephen R. G. 1995. The Persistence of Unemployment: Hysteresis in Canadian Labour Markets. Montreal: McGill-Queen's University Press.

Jones, Stephen R. G. and W. Craig Riddell. 1991. "The Measurement of Labour Market Dynamics with the Labour Market Activity Survey: The LMAS Filter.” Discussion Paper No. 91-17. UBC Department of Economics.

Kalbfleisch, J. D. and R. L. Prentice. 1980. The Statistical Analysis of Failure Time Data. New York: John Wiley \& Sons.

Kiefer, Nicholas M. 1988. "Economic Duration Data and Hazard Functions." Journal of Economic Literature XXVI (June): 646-679.

Krugman, Paul. 1994. "Past and Prospective Causes of High Unemployment." Federal Reserve Bank of Kansas City Economic Review 79(4)(Fourth Quarter): 23-43.

Lancaster, Tony. 1990. The Econometric Analysis of Transition Data. Cambridge: Cambridge University Press.

- 1979. "Econometric Methods for the Duration of Unemployment." Econometrica 47(4)(July): 939-956.

Lancaster, Tony and Stephen Nickell. 1980. "The Analysis of Re-Employment Probabilities for the Unemployed." The Journal of the Royal Statistical Society. Series A, 143 (Part 2): $141-165$.

Lauzon, Darren. 1995. “The Duration of Joblessness Following Displacement.” W-95-1. Applied Research Branch, Strategic Policy, Human Resources Development Canada.

Lawless, J. F. 1982. Statistical Models and Methods for Lifetime Data. New York: John Wiley \& Sons.

Lee, Elisa T. 1980. Statistical Methods for Survival Data Analysis. Belmont, CA: Lifetime Learning Publications. 
Lee, Thomas W., June G. Morita and Richard T. Mowday. 1989. "Introducing Survival Analysis to Organizational Researchers: A Selected Application to Turnover Research.” Journal of Applied Psychology 74(2): 280-292.

Lindeboom, Maarten and Jules Theeuwes. 1991. "Job Duration in the Netherlands: The CoExistence of High Turnover and Permanent Job Attachment." Oxford Bulletin of Economics and Statistics 53(3): 243-260.

Lynch, Lisa M. 1989. “The Youth Labor Market in the Eighties: Determinants of ReEmployment Probabilities for Young Men and Women.” Review of Economics and Statistics LXXI (1)(February): 37-45.

Michaud, Sylvie, Mike Egan, George Lemaitre and T. Scott Murray. 1991. "Invisible Seams? The Experience with the Canadian Labour Market Activity Survey." In 1991 Annual Research Conference Proceedings, 715-730. U.S. Bureau of Census.

Narendranathan, W. and M. B. Stewart. 1993. "How Does the Benefit Effect Vary as Unemployment Spells Lengthen.” Journal of Applied Econometrics 8: 361-381.

Poloz, Stephen S. and Gordon Wilkinson. 1992. "Is Hysteresis a Characteristic of the Canadian Labour Market? A Tale of Two Studies.” Working Paper No. 92-3. Ottawa: Bank of Canada.

Ravenscraft, David J. and F. M. Scherer. 1991. "Divisional Sell-Off: A Hazard Function Analysis." Managerial and Decision Economics 12: 429-438.

Raymond, Jennie E., T. Randolph Beard and Daniel M. Gropper. 1993. "Modelling the Consumer's Decision to Replace Durable Goods: a Hazard Function Approach.” Applied Economics 25: 1287-1292.

SAS/STAT Software: Changes and Enhancements, Release 6.07. 1992. SAS Technical Report P229. Cary, NC: SAS Institute.

Swaim, Paul and Michael Podgursky. 1992. “The Distributional Shape of Unemployment Duration: A Reconsideration." The Review of Economics and Statistics 76 (November): $712-721$. 


\section{Appendix I}

\section{Estimating the length of the UI benefit stream for individual LMAS records}

The estimated weeks of UI benefits assigned to each unemployed individual in the LMAS data base was computed, as much as it was possible, to be in accordance with the UI benefit and eligibility formulas that prevailed over the period 1988-90. The estimates for both entrance requirements and UI benefits first involved estimating the number of weeks an individual had worked in the 52 weeks preceding the period of unemployment. This 52 -week period is referred to as the qualifying period.

For individuals with unemployment spells beginning in 1988 or 1989, the entrance requirement ranges from 10 to 14 weeks of employment in the qualifying period and is estimated according to the rate of unemployment prevailing in the province of residence at the time the unemployment spell started. ${ }^{1}$ For individuals with unemployment spells beginning in 1990, the entrance requirement is 14 weeks, the result of a legislative lapse in reinstating the variable entrance requirement in 1990.

For individuals who satisfy the minimum entrance requirement, the number of weeks of UI benefits is estimated in accordance with the following three-phase benefit schedule:

(1) Initial benefits are calculated as the number of weeks of insurable employment in the 52-week qualifying period up to a maximum of 25 weeks.

(2) Labour-force extended benefits are calculated as one week of benefits for every two weeks of insurable employment in the qualifying period in excess of 26 weeks of employment up to a maximum of 13 weeks.

(3) Regional extended benefits are calculated as two weeks of benefits for every 0.5 percentage point that the provincial unemployment rate exceeds 4 per cent, up to a maximum of 32 weeks.

The full stream of UI benefits is the sum of items (1), (2), and (3) up to a maximum of 50 weeks. Given the complexity of the calculation, no attempt was made to fine-tune the estimate to account for the more stringent entrance requirements faced by repeat claimants.

1. UI entrance requirements and regional extended benefits are actually computed on the basis of the unemployment rates prevailing in sub-provincial regions but such computations could not be done here because the LMAS data are not disaggregated below the provincial level. 


\section{Bank of Canada Working Papers}

1997

97-1 Reconsidering Cointegration in International Finance:

Three Case Studies of Size Distortion in Finite Samples

M.-J. Godbout and S. van Norden

97-2 Fads or Bubbles?

H. Schaller and S. van Norden

97-3 La courbe de Phillips au Canada: un examen de quelques hypothèses

J.-F. Fillion and A. Léonard

97-4 The Liquidity Trap: Evidence from Japan

I. Weberpals

97-5 A Comparison of Alternative Methodologies for

Estimating Potential Output and the Output Gap

C. Dupasquier, A. Guay

and P. St-Amant

97-6 Lagging Productivity Growth in the Service Sector:

Mismeasurement, Mismanagement or Misinformation?

D. Maclean

97-7 Monetary Shocks in the G-6 Countries: Is There a Puzzle?

B. S.C. Fung and M. Kasumovich

97-8 Implementation of Monetary Policy in a Regime with Zero Reserve Requirements

K. Clinton

97-9 Mesures du taux d'inflation tendenciel

T. Laflèche

97-10 The Structure of Interest Rates in Canada:

Information Content about Medium-Term Inflation

J. Day and R. Lange

97-11 A Band-Aid Solution to Inflation Targeting

R. Amano, R. Black, and M. Kasumovich

97-12 A Micro Approach to the Issue of Hysteresis in Unemployment::

Evidence from the 1988-1990 Labour Market Activity Survey

G. Wilkinson

\section{6}

96-12 The Commodity-Price Cycle and Regional Economic Performance in Canada

M. Lefebvre and S. Poloz

96-13 Speculative Behaviour, Regime-Switching and Stock Market Crashes S. van Norden and H. Schaller

96-14 L'endettement du Canada et ses effets sur les taux d'intérêt réels de long terme J.-F. Fillion

96-15 A Modified P*-Model of Inflation Based on M1 J. Atta-Mensah

Earlier papers not listed here are also available.

Single copies of Bank of Canada papers may be obtained from

Publications Distribution, Bank of Canada, 234 Wellington Street Ottawa, Ontario K1A 0G9

E-mail: publications@bank-banque-canada.ca

WWW: http://www.bank-banque-canada.ca/

FTP: $\quad$ ftp.bank-banque-canada.ca (login: anonymous, to subdirectory

/pub/publications/working.papers/) 